\title{
1 Effect of concentration on shear and extensional rheology of guar gum solutions
}

2 M.D. Torres ${ }^{\mathrm{a}, \mathrm{b}}$, B. Hallmark ${ }^{\mathrm{a}}$ and D.I. Wilson ${ }^{\mathrm{a}}$

3 aDepartment of Chemical Engineering and Biotechnology, New Museums Site, University of Cambridge, Pembroke St, Cambridge, CB2 3RA, UK.

5 bepartment of Chemical Engineering, University of Santiago de Compostela, Lope Gómez de 6 Marzoa St, Santiago de Compostela, E-15782, Spain.

7

8

9

10

11

Submitted to

12

13

Food Hydrocolloids

14

15

Revised Manuscript

16

17

January 2013

18

19

20

(C) MDT, BH and DIW 


\section{Effect of concentration on shear and extensional rheology of guar gum solutions}

M.D. Torres · B. Hallmark · D.I. Wilson

\section{Abstract}

The steady shear and extensional rheology of aqueous guar gum solutions was studied for concentrations, $C$, ranging from $1 \mathrm{~g} / \mathrm{L}$ to $20 \mathrm{~g} / \mathrm{L}$. Extensional rheometry measurements were made using the Cambridge Trimaster filament-stretching device. The steady shear tests indicated a transition between a semi-dilute regime, below $10 \mathrm{~g} / \mathrm{L}$, and an entangled regime at higher concentrations. The solutions were shear-thinning solutions and obeyed the unmodified Cox-Merz rule in the dilute regime, but deviated from Cox-Merz and exhibited strongly viscoelastic behaviour at higher concentrations. The surface tension at higher concentration also deviated from the Szyszkowski model, exhibiting behaviour consistent with entanglement. The filament-thinning data did not fit the model for polymer solution behaviour presented by Entov and Hinch (1997), but gave a good fit to a modified form where time was normalized by the time for filament break-up. This scaling was independent of concentration effects, as reported by Chesterton et al. (2011) for cake batters. The modified model parameters approached asymptotic values for entangled solutions. The estimated apparent extensional viscosity exhibited a peak at unit strain followed by a constant value. The former increased as $C^{\mathrm{n}}$, where $n>1$, while the latter increased linearly with $C$.

Department of Chemical Engineering, University of Santiago de Compostela, Lope Gómez de Marzoa St, Santiago de Compostela, E-15782, Spain.

B. Hallmark ( $ه)$

Department of Chemical Engineering and Biotechnology, New Museums Site, University of Cambridge, Pembroke St, Cambridge, CB2 3RA, UK.

e-mail address: bh206@cam.ac.uk

D.I. Wilson

Department of Chemical Engineering and Biotechnology, New Museums Site, University of Cambridge, Pembroke St, Cambridge, CB2 3RA, UK. 


\section{$41 \quad$ Nomenclature}

\section{Roman}

$a$

fitting parameter, Szyszkowski equation, N/m

$b \quad$ fitting parameter of Szyszkowski equation, $\mathrm{g} / \mathrm{L}$

$b^{\prime} \quad$ parameter Equation [16], -

Bo $\quad$ Bond number, -

C concentration, $\mathrm{g} / \mathrm{L}$

$c^{*} \quad$ critical concentration, $\mathrm{g} / \mathrm{L}$

$D_{b} \quad$ diameter at break-up $(\mu \mathrm{m})$

$D_{\text {mid }} \quad$ diameter of the filament at midpoint $(\mu \mathrm{m})$

$D_{0} \quad$ initial sample diameter $(\mu \mathrm{m})$

$D_{1} \quad$ diameter of the filament when first formed $(\mu \mathrm{m})$

F normal force correction, N

$F_{\text {normal }} \quad$ normal force generated by the flow between plates, $\mathrm{N}$

$k \quad$ time constant, $\mathrm{s}^{1-n}$

$g \quad$ gravitational constant, $\mathrm{m} / \mathrm{s}^{2}$

$G^{\prime} \quad$ storage modulus, $\mathrm{Pa}$

$G^{\prime \prime} \quad$ loss modulus, $\mathrm{Pa}$

$L \quad$ number of relaxation times, -

$M_{n} \quad$ number-average molar mass, $\mathrm{g} / \mathrm{mol}$

$M_{w} \quad$ weight-average molar mass, $\mathrm{g} / \mathrm{mol}$

$M_{z} \quad$ higher-average molar mass, $\mathrm{g} / \mathrm{mol}$

$n \quad$ flow index, -

$N_{1} \quad$ first normal stress difference, $\mathrm{Pa}$

$N_{2} \quad$ second normal stress difference, $\mathrm{Pa}$

$N_{T r} \quad$ Trouton number, -

$p \quad$ probability, -

$R_{p p} \quad$ radius of parallel-plate geometry, $\mathrm{m}$ 
$R^{2} \quad$ square of the correlation coefficient, -

$t \quad$ time, $\mathrm{s}$

$t_{\text {cap }} \quad$ capillary time, $\mathrm{s}$

$t_{F 0} \quad$ time to capillary break-up (water), $\mathrm{s}$

$t_{F} \quad$ time to capillary break-up, s

$T \quad$ torque, $\mathrm{N} \mathrm{m}$

$X \quad$ filament shape factor, Equation (5), 


\section{Greek}

\begin{tabular}{|c|c|}
\hline$\varepsilon$ & Hencky strain, - \\
\hline$\varepsilon$ & Hencky strain rate, $\mathrm{s}^{-1}$ \\
\hline$\dot{\gamma}$ & shear rate, $\mathrm{s}^{-1}$ \\
\hline$\dot{\gamma}_{R}$ & shear rate experienced at the rim of the parallel plates, $\mathrm{s}^{-1}$ \\
\hline$\Gamma$ & surface tension between liquid phase and the air, $N / m$ \\
\hline$\Gamma_{0}$ & surface tension between the solvent and air, $\mathrm{N} / \mathrm{m}$ \\
\hline$\eta_{\text {app }}$ & apparent viscosity, $\mathrm{Pa} \mathrm{s}$ \\
\hline$\eta_{e}$ & estimated apparent extensional viscosity, $\mathrm{Pa} \mathrm{s}$ \\
\hline$\eta_{0}$ & zero-shear-rate viscosity, $\mathrm{Pa} \mathrm{s}$ \\
\hline$\eta_{p}$ & polymeric contribution to the viscosity, $\mathrm{Pa} \mathrm{s}$ \\
\hline$\eta_{s}$ & solvent viscosity, $\mathrm{Pa} \mathrm{s}$ \\
\hline$\left|\eta^{*}\right|$ & magnitude of the complex viscosity, $\mathrm{Pa}$ s \\
\hline$\lambda$ & relaxation time, $\mathrm{s}$ \\
\hline$\rho$ & density, $\mathrm{kg} / \mathrm{m}^{3}$ \\
\hline$\tau$ & shear stress, $\mathrm{Pa}$ \\
\hline$\omega$ & angular frequency, $\mathrm{Hz}$ \\
\hline & angular velocity, $\mathrm{rad} / \mathrm{s}$ \\
\hline
\end{tabular}


44 Solutions of water-soluble polysaccharides such as guar gum are widely used as thickeners, 45 stabilisers or gelling agents for food applications as well as in pharmaceutical, biomedical, chemical 46 and cosmetic products (Rosell et al., 2007). The molecular interactions between the polymer and water as well as polymer chain length determine the rheology of these solutions; polysaccharide chemical structure and size can, therefore, be exploited to develop new products, control processing quality and optimise the design of process equipment (Durand, 2007).

51 Guar gum is a galactomannan and one of the most cost effective natural hydrocolloids due to its ready availability and ease of manufacture by extraction from Cyamopsis tetragonolobus seeds (Cunha et al., 2007). This long-chain polysaccharide biopolymer is highly polydisperse 54 (Sittikijyothin et al., 2005), has a semiflexible random coil conformation composed of a linear mannan backbone bearing side chains of a single galactose unit (Imeson, 2010), and contains a mannose to galactose ratio of $\sim 1.6-1.8: 1$ (Cunha et al., 2007). Aqueous guar gum solutions are widely used in food products (e.g. Miquelim and Lannes, 2009; Moreira et al., 2011) at different concentrations as a thickening and stabilising agent (Duxenneuner et al., 2008; Bourbon et al., 2010). In contrast to synthetic polymers, guar gum can form highly viscous solutions at low concentrations $(<1 \%)$ which are relatively insensitive to $\mathrm{pH}$, addition of electrolytes and heating (Sittikijyothin et al., 2005).

62

63 As a viscosity modifier, knowledge of the effect of concentration on solution rheology is required for both product and process design (Moreira et al., 2011). The shear rheology of aqueous guar gum solutions has been investigated by many researchers who have probed structure-function-property parameters to gain insight into how, for example, molecular structure and solubility affect the resultant solution properties (e.g., Launay et al., 1997; Oblonsek et al., 2003; Cunha et al., 2005;

68 Chenlo et al., 2009, 2010). Guar gum solutions usually exhibit non-Newtonian, shear-thinning, 69 behaviour, where the apparent viscosity decreases with increasing shear rate. The apparent viscosity depends mainly on the molar mass while synergistic interactions are determined by the mannose/galactose ratio and the fine structure of the galactomannan chain. 
73 The majority of studies of guar gum rheology have considered shear rheology: relatively few have 74 investigated the extensional rheology of these solutions despite its importance in many food processing operations, consumer perception studies and product quality evaluation (Padmanabhan $e t$ al., 1995; Bourbon et al., 2010). Much of the work on extensional rheology has considered well characterised, model synthetic polymer solutions, and there is little published on the behaviour of systems containing guar gum and its derivatives, besides that by Tatham et al. (1995), Duxenneuner et al. (2008) and Bourbon et al. (2010). Duxenneuner et al. (2008) presented a comprehensive study of the shear and extensional rheological properties of hydroxypropyl ether guar gum solutions at concentrations up to $5 \mathrm{~g} / \mathrm{L}$. They investigated the effect of concentration on either the characteristic relaxation times or the transient uniaxial apparent extensional viscosities of dilute and semidilute modified guar gum solutions using a capillary breakup extensional rheometer (CaBER) device. Bourbon et al. (2010) studied the steady shear and extensional flow of aqueous guar gum solutions with concentrations between $0.39-0.97 \mathrm{~g} / \mathrm{L}$. They reported that the break-up time, relaxation time and elastic modulus increased with increasing polymer concentration. These results were confirmed here. The use of these devices to study biopolymers is increasing, including entagled cellulose solutions (Haward et al., 2012) and pitcher plant liquids (Gaume and Forterre, 2007).

This paper presents an investigation of the effects of concentration on the shear and extensional rheology of guar gum solutions, extending previous work undertaken by other researchers by examining a wider range of solution concentrations $(1-20 \mathrm{~g} / \mathrm{L}$, covering the range from dilute to entangled behaviour), and linking these observations to synthetic polymer solution behaviour. The aim is to improve the understanding of the rheological behaviour of guar gum solutions in extension to allow these materials to be used more efficiently, with reduced development time.

97 The present work follows on from investigations of bubbly liquids with a non-Newtonian liquid phase (Torres et al., 2013) and moderately high bubble volume fractions (25\%), where the presence

99 of a significant number of bubbles gave rise to viscoelastic behaviour that could not be described 100 adequately by the existing literature. Similar findings were reported for cake batters by Meza et al. 
101 (2011) and Chesterton et al., (2011). The results reported here allow the contribution from the guar 102 gum solutions to the viscoelastic behaviour observed in guar gum-based bubbly liquids to be 103 computed.

106 Measurements of extensional rheology are needed to characterise fluid properties fully (Odell \& 107 Carrington, 2006). Experimental investigation of extensional flows is challenging, particularly for 108 viscoelastic materials (Vadillo et al., 2012a), partly due to difficulties in creating a purely 109 extensional flow. During a shear deformation, the fluid elements within the material move in the 110 same direction and slide over each other, whereas in extension the fluid elements either move away 111 or towards each other as the material is stretched or compressed, respectively (Entov and Hinch, 112 1997). Various testing methods are used (Steffe, 1996; Macosko, 1994) and this study employs the

113 filament thinning technique. The relaxation and decay of a necked sample is controlled by a balance

114 between inertial, viscous, elastic, gravitational and capillary forces (Anna and McKinley, 2001).

116 The extensional viscosity of synthetic polymer solutions is sensitive to molecular weight and extent 117 of long chain branching (Anna and McKinley, 2001). Addition of polymer increases the shear and 118 extensional viscosity of the fluid and promotes viscoelastic behaviour, which can strongly affect 119 filament thinning and break-up mechanisms (McKinley, 2005; Tuladhar and Mackley, 2008; Vadillo 120 et al., 2010; Haward et al., 2012). There are very relatively few investigations of the effect of 121 concentration on the extensional properties of synthetic polymer solutions. Behaviour analogous to 122 shear rheology is expected, where at higher concentrations the molecules entangle with each other, 123 limiting the length to which the molecule can be extended. Another effect of concentration is the 124 impact of the polymer chain on the flow field itself (Gupta et al., 2000). A transition from the dilute 125 to the entangled regime behaviour is therefore expected for guar gum solutions.

127 Many mathematical approximations for extensional rheology behaviour have been implemented and 128 several closed form constitutive equations exist (Bird et al., 1987; Larson, 1988). Most testing has 129 been conducted with shear flows, and the reliability of these equations for strongly extensional 
130 flows, where a substantial degree of stretching is anticipated, is not well understood and the

131 available constitutive equations are not able to predict all the measured transient extensional stresses

132 (Gupta et al., 2000).

133

134 Materials and Methods

135 Sample preparation

136 Commercial guar gum was supplied by Sigma-Aldrich (batch no. 041M0058V, India) with a

137 reported molecular weight of $2.9 \times 10^{6} \mathrm{~g} / \mathrm{mol}$. The weight-average molar mass $\left(M_{\mathrm{w}}\right)$ was determined

138 by gel permeation chromatography (GPC) with a Dawn Heleos-II instrument (Wyatt Technologies)

139 at room temperature, around $21^{\circ} \mathrm{C}$, using a PL-aquagel-OH Mixed-H column $(7.5 \mathrm{~mm} \times 300 \mathrm{~mm}$,

140 Agilent Technologies), flow rate of $0.5 \mathrm{~mL} / \mathrm{min}$, polysaccharide concentration of $0.1 \%(\mathrm{w} / \mathrm{v})$ with

141 water as the solvent. A differential refractometer was used as the detector. Pullulan samples (Shodex

142 Denko) of $M_{\mathrm{w}} 5.9 \times 10^{3}, 1.18 \times 10^{4}, 4.73 \times 10^{4}, 2.12 \times 10^{5}$ and $7.88 \times 10^{5} \mathrm{~g} / \mathrm{mol}$ were used as standards.

143 This yielded a $M_{\mathrm{w}}$ value of $3.0 \times 10^{6} \mathrm{~g} / \mathrm{mol}$ and a small degree of polydispersity, characterised by $M_{\mathrm{w}} /$

$144 M_{\mathrm{n}}=1.13$ and $M_{\mathrm{z}} / M_{\mathrm{n}}=5.15$, where $M_{\mathrm{n}}$ and $M_{\mathrm{z}}$ are the number average molecular weight and higher

145 average molecular weight, respectively.

146

147 Aqueous solutions of guar gum at concentrations of 1, 2, 5, 10, 15 and $20 \mathrm{~g} / \mathrm{L}$ were prepared 148 following the procedure reported by Chenlo et al. (2010). The polymer was dispersed in tap water by 149 stirring at $1400 \mathrm{rpm}$ on a magnetic hotplate stirrer (VMS-C4 Advanced, VWR, UK) at room

150 temperature, between $19^{\circ} \mathrm{C}$ and $21^{\circ} \mathrm{C}$, overnight to ensure complete hydration of the guar gum.

151 Some air was incorporated into the solution during stirring and deaerated samples of the continuous

152 phase were obtained by centrifugation at $2250 \mathrm{rpm}(500 \mathrm{~g})$ for $5 \mathrm{~min}$. All samples were, at 153 minimum, duplicated.

\section{Shear rheology}

156 Shear rheological measurements (under steady and oscillatory shear) were performed on a Bohlin 157 CVO120HR controlled-stress rheometer (Malvern Instruments, Malvern, UK) using sand-blasted 158 parallel plates $(25 \mathrm{~mm}$ diameter and $1 \mathrm{~mm}$ gap) to prevent wall slippage. Preliminary tests with 
160 significant slip effects. Samples were loaded carefully to ensure minimal structural damage, and held

161 at rest for $5 \mathrm{~min}$ before testing to allow stress relaxation and temperature equilibration. A thin film of

162 a Newtonian silicone oil (viscosity $1 \mathrm{~Pa} \mathrm{~s}$ ) was applied to the exposed sample edges to prevent

163 evaporation. All measurements were made under isothermal conditions $\left(20^{\circ} \mathrm{C}\right)$ and, at minimum,

164 duplicated. Error bars corresponding to experiment variation of repeated tests are plotted where the

165 measurement uncertainty was greater than the symbol size.

166

167 Steady shear measurements

168 Viscous behaviour was investigated using steady shear measurements. The apparent viscosity, $\eta_{a p p}$,

169 was determined as function of shear rate, $\dot{\gamma}$, over the range of 0.1 to $1000 \mathrm{~s}^{-1}$. Samples were sheared

170 for $5 \mathrm{~s}$ at each shear rate in order to obtain steady-state. Since the shear rate varies with radial

171 position in the parallel plate geometry, the apparent viscosity data were calculated using (Steffe,

172 1996):

$$
\eta_{\text {app }}\left(\dot{\gamma}_{R}\right)=\frac{T}{2 \pi R_{p p}^{3} \dot{\gamma}_{R}}\left(3+\frac{d \ln T}{d \ln \dot{\gamma}_{R}}\right)
$$

174 where $\dot{\gamma}_{R}$ is the shear rate evaluated at the rim considering angular velocity and geometry, $R_{p p}$ is the

175 radius of the parallel plates and $T$ is the torque. Using linear regression, a relationship between the

176 torque and shear rate data can be obtained in this study, being the slope term defined as $\frac{d \ln T}{d \ln \dot{\gamma}_{R}}$.

178 The shear-thinning behaviour of guar gum solutions was fitted to the Cross-Williamson model 179 (Cross, 1965):

$$
\frac{\eta_{a p p}}{\eta_{0}}=\frac{1}{1+k \dot{\gamma}^{(1-n)}}
$$

181 where $\eta_{0}$ is the zero-shear rate viscosity, $k$ is the time constant and $n$ is the flow index. 
183 The normal force, $F_{\text {normal }}$, generated by the flow between plates was measured in steady shear tests

184 on the Bohlin rheometer. Measurements of axial thrust were used to estimate the normal stress 185 difference, $N_{1}-N_{2}$ via (Steffe, 1996):

$$
N_{1}-N_{2}=\frac{2 F_{\text {normal }}}{\pi R_{p p}^{2}}\left(1+\frac{1}{2} \frac{d \ln F_{\text {normal }}}{d \ln \dot{\gamma}_{R}}\right)
$$

187 The normal stress difference data were compared to the computed shear stress and apparent viscosity results to give an indication of when elastic forces became significant. The normal force correction due to inertial effects was estimated using (Kulicke et al., 1977):

$$
F=-0.075 \pi \rho \Omega^{2} R_{p p}^{4}
$$

191 where $\Omega$ is the angular velocity and $\rho$ the liquid density. This force correction was negligible for all tests conducted here.

\section{Oscillatory shear measurements}

195 Viscoelastic behaviour was studied using small amplitude oscillatory shear testing. A strain sweep was performed from 0.01 to $10 \%$ at frequencies of 0.01 and $10 \mathrm{~Hz}$ prior to each frequency sweep to ensure that tests were performed in the linear viscoelastic (LVE) region for each solution. Frequency sweeps were carried out over the range 0.01 to $10 \mathrm{~Hz}$ at a strain amplitude of $1 \%$ (well below the LVE limit) and the storage modulus, $G^{\prime}$, loss modulus, $G^{\prime \prime}$, and magnitude of the complex dynamic viscosity, $\left|\eta^{*}\right|$, were determined using the rheometer software.

\section{Extensional rheology}

203 Extensional rheology was investigated using the Cambridge Trimaster, a high-speed filament stretch and break-up device described by Vadillo et al. (2010). The apparatus consists of two cylindrical 1.2 mm diameter stainless steel stubs which are moved vertically apart at high speed with high spatial precision. Measurements reported here featured an initial gap spacing of $0.6 \mathrm{~mm}$, final gap spacing of $1.5 \mathrm{~mm}$ and piston separation speed of $75 \mathrm{~mm} \mathrm{~s}^{-1}$. All experiments were performed at least in duplicate in an air-conditioned room at $20{ }^{\circ} \mathrm{C}$. 
210 The filament stretching and thinning profiles were monitored using a high speed camera (Photron

211 Fastcam $1024 \mathrm{PCI}$ ) which allows the diameter of the filament midpoint, $D_{\text {mid }}(t)$, to be measured to $212 \pm 0.1 \mu \mathrm{m}$ at a rate of 6000 frames per second. The device did not feature a force transducer so 213 separating forces were not recorded. Estimates of the apparent extensional viscosity, $\eta_{e}$, can be 214 obtained from the filament regime using (Vadillo et al., 2010):

$$
\eta_{e}=(2 X-1) \frac{-\Gamma}{d D_{m i d}(t) / d t}
$$

216 where $X$ is a coefficient which accounts for the deviation of the filament shape from a uniform

217 cylinder due to inertia and gravity, $\Gamma$ is the surface tension between the liquid phase and the air, and $t$

218 is the elapsed time. Several authors report $X$ values of $\sim 0.7$ for polymer solutions at approximately

219 zero Reynolds number (McKinley and Tripathi, 2000; Vadillo et al., 2010) whereas $X$ values

220 equalling 0.5912 have been derived by Eggers, 1997 (and further reported by McKinley and

221 Tripathi, 2000) from the universal similarity solution describing the breakup of a Newtonian fluid at

222 non-zero Reynolds numbers. Although the non-zero Reynolds number condition can be shown to be

223 met for the solution containing $1 \mathrm{~g} / \mathrm{L}$ of guar gum, it introduces an unphysical discontinuity in the

224 trends of extensional viscosity as a function of concentration, presented later, hence $X$ values

225 equalling 0.7 were used in Equation (5).

226

227 The equilibrium surface tension between the guar gum solutions and air at $21{ }^{\circ} \mathrm{C}$ was determined

228 experimentally using the sessile drop method with a Kruss Drop Shape Analyser 100 device. Values

229 reported are the mean from at least ten measurements.

230

231 Filament measurements were obtained using automatic image treatment in the Cambridge Trimaster

232 software. Three characteristic diameters were recorded: $D_{0}$, the initial sample diameter, being that of

233 the plates; $D_{1}$, the diameter of the filament when first formed, and $D_{b}$, the diameter at break-up. The

234 symmetry of the sample during thinning was checked by comparing the filament diameter at

235 positions $100 \mu \mathrm{m}$ above and below the mid-plane, and asymmetric results discarded. The influence

236 of gravity is characterised by the Bond number: 


$$
B o=\frac{\rho g D_{0}^{2}}{4 \Gamma}
$$

238 where $g$ is the gravitational constant. The sample density was estimated by weighing a $150 \mathrm{~mL}$ 239 plastic cup filled with guar gum solution. The surface was levelled off using a spatula, the cup 240 weighed and the density determined as the ratio of the mass of sample to cup volume. The material 241 parameters lie in the range $\rho \sim 1086 \mathrm{~kg} \mathrm{~m}^{-3}, g=9.81 \mathrm{~m} \mathrm{~s}^{-2}, D_{0}=1.2 \mathrm{~mm}$ and

$242 \Gamma \sim 0.067 \mathrm{~N} \mathrm{~m}^{-1}$, giving $B o$ values around 0.04 . Gravitational effects are therefore expected to be 243 negligible. Transient profiles recorded on the Trimaster for guar gum concentrations of $1 \mathrm{~g} / \mathrm{L}, 10 \mathrm{~g} / \mathrm{L}$ 244 and $20 \mathrm{~g} / \mathrm{L}$ can be found in the Supplementary Data.

246 The Hencky strain, $\varepsilon$, experienced by the sample at the axial midplane at time $t$ is defined using the 247 midfilament diameter:

$$
\varepsilon=2 \ln \left(\frac{D_{1}}{D_{\text {mid }}(t)}\right)
$$

249 The apparent extensional viscosity is compared with the apparent viscosity via the Trouton number,

$250 N_{T r}$. This is the ratio of apparent extensional to shear viscosity at equivalent shear rates, which, for 251 non-Newtonian fluids is given by (Steffe, 1996):

$$
N_{T r}=\frac{\eta_{e}(\dot{\varepsilon})}{\eta_{a p p}(\sqrt{3} \dot{\varepsilon})}
$$

where $\varepsilon$ is the Hencky strain rate. For Newtonian fluids at small strains, $N_{\operatorname{Tr}}=3$. Departure from this

254 result is due to viscoelastic material behaviour (Steffe, 1996).

Several studies (Bazilevsky et al.,1990; Renardy, 1994, 1995; Brenner et al., 1996; Bazilevsky et al., 1997; Entov and Hinch,1997) have presented theoretical treatments predicting the evolution of the midfilament diameter for both Newtonian and viscoelastic fluids. Entov and Hinch modelled the fluid as a FENE material and reported that the midfilament diameter decreased exponentially with

260 time: 


$$
D_{\text {mid }}(t)=\left(\frac{\eta_{p} D_{1}^{4}}{2 \lambda \Gamma}\right)^{1 / 3} \exp \left(\frac{-t}{3 \lambda}\right)
$$

262 where $\eta_{p}=\eta_{0}-\eta_{s}$ is the polymeric contribution to the viscosity ( $\eta_{s}$ is the solvent viscosity), and $\lambda$ is the characteristic relaxation time of the polymer.

The analysis above applies to elastic fluids described by a single time constant. However, in reality, polymer solutions can have a spectrum of time constants. Entov and Hinch (1997) showed that for 'intermediate elastic times', i.e., after viscous effects have become negligible relative to elastic effects and before finite extensibility of the dumbbells becomes important, Equation [9] can be generalized to:

$$
\frac{D_{m i d}(t)}{D_{1}}=\left(\sum_{i=1}^{L}\left(\frac{\eta_{p} D_{1}}{2 \lambda_{i} \Gamma}\right) \exp \left(\frac{-t}{\lambda_{i}}\right)\right)^{1 / 3}
$$

The second type of characteristic time scale of importance in elasto-capillary thinning studies is the capillary time, $t_{c a p}$, which is the timescale for characterising capillary break-up in viscous Newtonian fluids (Anna and McKinley, 2001). The capillary time quantifies the relative effects of capillary and viscous forces: viz.

$$
t_{\text {cap }}=\frac{\eta_{0} D_{1}}{2 \Gamma}
$$

where $D_{1}$ is used instead of $D_{0}$ in this study since the initial filament diameter $\left(D_{1}\right)$ varied widely between notionally identical samples. Similar assumptions were previously made for cake batters with good results (Chesterton et al., 2011). Further details of the apparatus and method are given in papers that describe other studies with this instrument (Vadillo et al., 2010).

\section{Statistical analysis}

Linear and nonlinear regressions were used to extract rheological parameters. The parameters of the models considered were determined from the experimental data with a one-factor analysis of variance (ANOVA) using PASW Statistics (v.18, IBM SPSS Statistics, New York, USA). When the analysis of variance indicated differences among means, a Scheffé test was performed to differentiate means with $95 \%$ confidence $(p<0.05)$. 


\section{Results and Discussion}

\section{Surface tension}

290 The results obtained for aqueous guar gum solutions in Figure 1 shows that the guar gum reduces the

291 surface tension of water, by up to $6 \mathrm{mN} \mathrm{m}^{-1}$. The data exhibit the trend expected for surfactant 292 solutions, albeit with a modest effect. The influence of guar gum concentration was satisfactorily

293 fitted to the Szyszkowski equation (Szyszkowski, 1908):

$$
\frac{\Gamma}{\Gamma_{0}}=1-a \ln \left(1+\frac{C}{b}\right)
$$

where $\Gamma_{0}$ is the surface tension of the solvent, $C$ the concentration of the surfactant and $a$ and $b$ are fitting parameters. The data in Figure 1 suggest that the solutions exhibit behaviour associated with the onset of entanglement near $5 \mathrm{~g} / \mathrm{L}$, which is in reasonable agreement with the value of $7 \mathrm{~g} / \mathrm{L}$ reported for other guar gum solutions at $25{ }^{\circ} \mathrm{C}$ by Marangoni and Narine (2002). These surface tension values were consistent with those reported for aqueous guar gum dispersions by Moreira et al. (2012).

\section{Steady shear measurements}

303 Flow curves for aqueous guar gum solutions at several concentrations are shown in the form of shear rate sweeps in Figure 2. The apparent viscosity at each shear rate increases noticeably with polymer concentration. In all cases, the solutions exhibit shear-thinning behaviour, where the apparent viscosity decreases with shear rate, and the extent of shear-thinning increases with concentration. Guar gum solutions at concentrations above $5 \mathrm{~g} / \mathrm{L}$ exhibited strong shear-thinning behaviour, as reported by Chenlo et al. (2010); these authors found that the shear rate at which the zero-shear rate viscosity plateau ended depended on polymer concentration, which is also evident in this Figure.

311 The data gave satisfactory fits $\left(R^{2}>0.996\right.$, standard error $<0.032 \mathrm{~Pa}$ s $)$ to the Cross-Williamson

312 model, Eqn. [2], and the parameters $\eta_{0}, k$ and $n$ obtained are summarised in Table 1 . The $\eta_{0}$ and $k$ 313 values increased significantly with increasing polymer concentration, while the variation in $n$ was 314 modest, the values $0.23-0.31$ being similar to those reported for synthetic polymer solutions. The 
315 increase of $\eta_{0}$ with polymer concentration indicates the establishment of a greater number of links

316 between the biopolymer molecules and depends on the molar mass and on interchain interactions. A

317 higher value of $k$ is attributed to an increase in chains entanglement density. Bourbon et al. (2010)

318 postulated that the freedom of movement of individual chains is progressively restricted and

319 consequently increases the time needed to form new entanglements to replace those destroyed by the

320 external deformation. Hence, the shear rates values at which the behaviour becomes shear-thinning

321 decrease as the concentration increases, as evident in Figure 2. These results were consistent with

322 those previously found for other guar gum solutions (Chenlo et al., 2010; Duxenneuer et al., 2008).

324 The normal stress difference data, $N_{1}-N_{2}$, presented in Figure 3(a) indicate that aqueous guar gum 325 solutions generate appreciable elastic responses at high shear rates. The normal stress difference, $N_{1^{-}}$ $326 N_{2}$, for guar gum solutions at $1 \mathrm{~g} / \mathrm{L}$ was practically negligible, whereas for $C=20 \mathrm{~g} / \mathrm{L} N_{1}-N_{2}$ 327 increased rapidly at shear rates above $1 \mathrm{~s}^{-1}$. This value at which $N_{1}-N_{2}$ increased noticeably was 328 shifted to higher shear rates at lower concentrations. The shear rate at which $N_{1}-N_{2}$ increased corresponds to the onset of noticeable shear-thinning in Figure 2.

The data in Figure 3(a) are plotted in dimensionless form in Figure 3(b). The normal stress difference is plotted as the approximate Weissenberg number, Wi $\left(W i=N_{1} / \tau \approx N_{1}-N_{2} / \tau\right)$ while the shear rate is presented as the dimensionless shear rate suggested by the Cross-Williamson model (the

334 product, $k \dot{\gamma}^{n}$, which may be interpreted as the rate of link breakage). The data sets follow a 335 common trend, with Wi increasing with breakage rate, which merits further investigation. The 336 results confirm that viscoelastic responses can be generated in guar gum solutions under steady 337 shear.

\section{Oscillatory shear measurements}

340 Selected mechanical spectra $\left(G^{\prime}\right.$ and $G^{\prime \prime}$ vs. angular frequency) of aqueous guar gum solutions

341 prepared at several concentrations are presented in Figure 4. The elastic modulus, $G^{\prime}$, related to the

342 elastic response of the system, and the viscous modulus, $G^{\prime \prime}$, related to the viscous response of the 343 system, increased at low frequency by roughly five orders of magnitude with increasing polymer 
344 concentration. The mechanical behaviour of the guar gum solutions was dependent on frequency and

345 followed the shape reported elsewhere for similar guar gum solutions (Steffe, 1996; Chenlo et al.

346 2010). In all cases, both moduli increased with frequency by roughly three orders of magnitude

347 between 0.01 and $10 \mathrm{~Hz}$. For low polymer concentrations below $5 \mathrm{~g} / \mathrm{L}, G^{\prime \prime}>G^{\prime}$ over the entire

348 frequency range investigated, indicating predominantly viscous behaviour (Figure 4a), whereas there

349 is a crossover in the moduli at higher concentration (above $10 \mathrm{~g} / \mathrm{L}$ ) and the elastic response prevails

350 at higher frequencies (Figure 4b). These results are similar to those reported for random coil

351 polymers. The crossover frequency (where $G^{\prime} \sim G^{\prime \prime}$ ) decreased from $4 \mathrm{~Hz}$ to $1 \mathrm{~Hz}$ as the

352 concentration increased from $10 \mathrm{~g} / \mathrm{L}$ to $20 \mathrm{~g} / \mathrm{L}$, as a consequence of longer relaxation times. Bourbon

353 et al. (2010) reported similar behaviour for several other random-coil polysaccharide solutions in

354 this concentration range. The viscoelastic behaviour of the guar gums solutions was predominantly

355 viscous over the range of angular frequencies for other concentrations, indicating that the entangled

356 regime is encountered between 5 and $10 \mathrm{~g} / \mathrm{L}$.

\section{Complex viscosity}

359 Figure 5 shows that the solutions obeyed the Cox-Merz rule, $\left|\eta^{*}(\omega)\right| \approx \eta(\dot{\gamma})$ where $\omega=\dot{\gamma}$, (Cox 360 and Merz, 1958), relating the apparent viscosity (steady shear flow) and the magnitude of the 361 complex viscosity (oscillatory shear flow) at a given frequency and shear rate at concentrations 362 below $10 \mathrm{~g} / \mathrm{L}$. There is a divergence in behaviour at high rates for the more concentrated solutions, 363 which are thought to lie in the entangled regime. The deviation is related to the elastic gel-like 364 structure, which is not affected during oscillatory measurements, but is broken during steady shear 365 tests such that the measured magnitude of the complex viscosity is larger than the apparent viscosity

366 (Steffe, 1996). Similar behaviour has been reported for synthetic polymers such as polyisobutylene

367 by Liang and Mackey (1994), who also found that the largest deviations occurred at higher angular 368 frequencies and shear rates.

370 Extensional measurements

371 Figure 6 shows the evolution of mid-filament diameter, $D_{\text {mid }}$, for different concentrations. The 372 diameter is determined by the balance of surface tension and viscous/elastic forces: viscous forces 
tend to stabilize the filament, while surface tension acts to destabilize it, causing the increasingly rapid decrease in the diameter until the filament breaks apart. The decrease in $D_{\text {mid }}$ with time is not

375 linear: there is a sharp step followed by an exponential decay, after which the rate of decay increases towards break-up at time $t_{\mathrm{F}}$. Similar trends were reported for other aqueous guar gum systems at different concentrations (Duxenneuner et al., 2008; Bourbon et al., 2010), and confirm nonNewtonian behaviour.

380 The time to break-up, $t_{\mathrm{F}}$, increased with polymer concentration and Figure 7 shows that an asymptote is reached around $10 \mathrm{~g} / \mathrm{L}$. The effect of concentration, $C$, on $t_{\mathrm{F}}$ fitted the empirical expression:

$$
t_{F}-t_{F 0}=1-\exp \left(\frac{C}{20}\right)
$$

where $t_{F 0}$ is the break-up time observed with water. The square of the correlation coefficient, $R^{2}$, was 0.995. This behaviour is consistent with the results obtained for the shear rheology, suggesting that above $10 \mathrm{~g} / \mathrm{L}$ guar gum solutions lie in the entangled region. The $t_{\mathrm{F}}$ values also increased with $D_{1}$ (see the inset on Figure 7), following an exponential dependency given by:

$$
t_{F}=15.2 \exp \left(0.0042 D_{1}\right)
$$

with the square of the correlation coefficient, $R^{2}$, being 0.998 . A similar dependency between $t_{\mathrm{F}}$ and

The individual data sets in Figure 6 collapsed to a common form when the capillary diameter,

393 normalised against $D_{1}$, as in Equation (16), was plotted against the timescale was normalised against $t_{\mathrm{F}}($ see Figure 8):

$$
\frac{D_{m i d}(t)}{D_{1}} \propto \exp \left(\frac{-t}{t_{F}}\right)
$$

397 The data sets were also analysed in the form employed by Anna and McKinley (2001) to present data obtained for Boger fluids, namely plots of $\left[D_{\text {mid }}(t) / D_{1}\right] v s$. $\left[t / t_{c a p}\right]$. These plots showed an initially linear region, characteristic of viscoelastic behaviour, followed by a sharp descent towards 
filament break-up at $t_{\mathrm{F}}$ (data not presented). The time scaling showed that the decay timescale and

401 the approach to break-up are not determined by the characteristic capillary time. Deviations from the simple form expected for a dilute polymer solution as discussed by Anna and McKinley (2001), were reported for another complex entangled biopolymeric system, cellulose in ionic liquid solutions, using a CaBER device by Haward et al. (2012). These authors showed very similar trends for the shear viscosity, linear viscoelastic and extensional data as the present work.

Anna and McKinley (2001) successfully fitted their data for synthetic polymer solutions to Equation (9), relating the observed behaviour to polymer relaxation times and the finite extensibility of polymer molecules. In the current study, however, poor agreement was obtained when experimental data were fitted to Equation (9), with one relaxation time, or to Equation (10) using up to eight relaxation times, as illustrated by the example in Figure 9. An alternative physical mechanism is

412 operating, which is consistent with those observations made by Tembely et al. (2012) and Vadillo et 413 al. (2012), where computational fluid dynamic simulations for predicting the fast filament stretching, relaxation and break up of low viscosity weakly elastic fluids were presented. The authors of this work have also tried mono and multi mode approach to fit the filament thinning of such fluids, rather unsuccessfully, using Oldroyd-B and FENE-CR constitutive equations.

418 Equation (9) was modified by the addition of an empirical constant, $b$, which yielded a significantly better fit to the experimental data (see Figure 9):

Chesterton et al. (2011) reported that their cake batter data fitted this empirical relationship for several different flours.

All the data sets fitted the expression shown in Equation (16) satisfactorily $\left(R^{2}>0.990\right)$. The empirical model proposed in Equation (16) exhibits the form expected for a Giesekus fluid (as reported by Yesilata et al., 2006); further exploration of this relationship is currently ongoing. The 
relaxation times and $b^{\prime}$ values obtained are presented in Figure 10. The relaxation times increase with increasing polymer concentration, approaching an asymptotic value of $17 \mathrm{~ms}$ around $10 \mathrm{~g} / \mathrm{L}$,

430 whereas the $b^{\prime}$ values decrease with concentration, approaching an asymptotic value of unity at 10

$431 \mathrm{~g} / \mathrm{L}$. Bourbon et al. (2010) reported the existence of two relaxation times for aqueous guar gum

432 solutions with values ranging from $\lambda_{1} \sim 15 \mathrm{~ms}$ and $\lambda_{2} \sim 1 \mathrm{~ms}$ for $1.9 \mathrm{~g} / \mathrm{L}$, to $\lambda_{1} \sim 58 \mathrm{~ms}$ and $\lambda_{2} \sim 4200$

$433 \mathrm{~ms}$ for $9.7 \mathrm{~g} / \mathrm{L}$. These data can be contrasted against those from this study where the relaxation time,

$434 \lambda_{1}$, ranges between $\lambda_{1} \sim 8 \mathrm{~ms}$ for $2.0 \mathrm{~g} / \mathrm{L}$ and $\lambda_{1} \sim 17 \mathrm{~ms}$ for $10 \mathrm{~g} / \mathrm{L}$. Bourbon et al. (2010) proposed

435 that the two relaxation times arise from the structure of the studied polysaccharides, one related to

436 the expansion of the polymeric chains, the other relating to interactions between the chains delaying

437 the relaxation phase.

438

439 Duxenneuner et al. (2008) studied modified guar gum solutions and reported that the relaxation time

440 followed a power-law scaling dependency in the semi-dilute concentration regime, from $3 c^{*}$ up to

$4419 c^{*}$. These authors defined $c^{*}$ as the critical micelle concentration, which can be identified as the

442 concentration where the surface tension data as a function of concentration deviate from the

443 Szyszkowski equation (Szyszkowski, 1908) that was given in Equation (12); they found that

$444 c^{*} \sim 0.58 \mathrm{~g} / \mathrm{L}$. These authors stated that this behaviour was a manifestation of increasing interactions

445 between hydroxypropyl ether guar gum molecules in solution with increasing concentration. The

446 relative weak dependency suggests that the interactions between chains were overall quite weak and

447 may be purely hydrodynamic in nature. We note that Haward et al. (2012) recently reported a strong

448 dependency of relaxation times with concentration of cellulose in an ionic liquid. They found that

449 the relaxation times obtained from CABER measurements initially increase slowly with

450 concentration and then climb more rapidly in the semi-dilute and entangled regimes.

452 Figure 11 shows that $t_{F}$ exhibits a linear dependency on the relaxation time parameter, $\lambda$. No further explanation is offered at this time as the physical basis of Equation (16) is not established.

The apparent extensional viscosity was estimated using Equation (5) and the results are presented in Figure 12. This analysis assumes that the equilibrium surface tension values in Figure 1 can be used 
to estimate the forces involved in extension; direct measurement of the force in the filament is required to confirm these values. Figure 12(a) plots the apparent extensional viscosity as a function of the Hencky strain. Since the apparent extensional viscosity profiles are a function of the

460 midfilament diameter, $D_{\text {mid }}$, which itself changes as a function of time, the values are governed by 461 the self-thinning of the filament, and are not a response to an imposed shear rate as in shear 462 rheometry. The apparent extensional viscosities increase sharply at low Hencky strains, exhibiting a 463 peak (at $\varepsilon \sim 1.2$ ) for concentrations above $10 \mathrm{~g} / \mathrm{L}$, where entanglement is believed to be important.

464 At higher strains, $\eta_{\mathrm{e}}$ approaches an asymptote, the value of which increases with concentration.

The effect of concentration on the peak and plateau values of the apparent extensional viscosity is presented in Figure 12(b). Both parameters increase with concentration, with the plateau value following a linear dependency but the peak value exhibiting an exponential dependency. Duxenneuner et al. (2010) reported two steady-state extensional trends for hydroxypropyl ether guar gum solutions: a linear dependence of the plateau values up to $\sim 3$ times the critical polymer concentration $\left(c^{*} \sim 0.58 \mathrm{~g} / \mathrm{L}\right)$, followed by a power-law dependence up to their highest-studied concentration (around $1 \mathrm{~g} / \mathrm{L}$ ) of $\sim 9$ times the critical polymer concentration.

The apparent extensional viscosities are now compared with the apparent viscosities via the Trouton number (i.e., $\eta_{e} / \eta_{a p p}$ ) evaluated at $0.1 \mathrm{~s}^{-1}$. Figure 13(a) shows the Trouton number values calculated for aqueous guar gum solutions against the Hencky strain. An exponential increase in the Trouton number with Hencky strain was observed in all cases. Moreover, the Trouton number decreased noticeably with an increase of polymer concentration (Figure 13(b)). This trend is consistent with those reported for derived guar gum solutions by Duxenneuner et al. (2010), who found that the

480 Trouton number values started as high as 440 for $0.1 \mathrm{~g} / \mathrm{L}$ and decreased to $16 \mathrm{for} 5 \mathrm{~g} / \mathrm{L}$ over a shear 481 rate range between $0.1 \mathrm{~s}^{-1}$ and $1000 \mathrm{~s}^{-1}$. They stated that the high values of Trouton number recorded at the lowest polymer concentration indicate that most of the extensional response is due to the 483 alignment and extension of individual chains, with increasing effects of chain-chain interactions at higher polymer contents. 
487 The shear and extensional rheology of aqueous solutions of guar gum with concentrations has been studied over the range $1 \mathrm{~g} / \mathrm{L}$ to $20 \mathrm{~g} / \mathrm{L}$. The molecular weight of the guar gum was $3.0 \times 10^{6} \mathrm{~g} / \mathrm{mol}$, with a polydispersity $\left(\mathrm{M}_{w} / \mathrm{M}_{n}\right)$ of 1.13 . The behaviour of the guar gum solutions was predominantly viscoelastic, with the extent of the viscoelasticity being determined by polymer concentration. At concentrations below $10 \mathrm{~g} / \mathrm{L}$, the rheological behaviour was consistent with the polymer being in a non-entangled state, but at concentrations above $10 \mathrm{~g} / \mathrm{L}$ the data suggested the presence of entanglement and the formation of an elastic, gel-like, structure. The measured surface tension values also exhibited behaviour reminiscent of micelle formation at concentrations in the entangled regime.

497 The steady shear data fitted the Cross-Williamson model well and suggests that shear thinning arises

498 from breakdown of interactions between polymer strands. The viscoelastic response accompanying 499 breakdown, quantified by the first normal stress difference, coincided with the onset of noticeable 500 shear-thinning. Plots of the estimated Weissenberg number against the normalised shear rate 501 calculated from the Cross-Williamson model showed a common trend which merits further 502 investigation.

504 The filament stretching data did not fit the model presented by Entov and Hinch (1997) which has 505 been successfully used by several workers to describe the extensional behaviour of synthetic 506 polymer solutions, even when eight relaxation times were used. An empirical modification of the 507 Entov and Hinch model, adding a time-independant constant, however, gave good fits with only one 508 relaxation time. This empirical modification exhibits the form expected for a Giesekus fluid, as 509 reported by Yesilata et al., 2006; further exploration of this relationship is ongoing. Plots of the 510 normalised filament diameter against normalised time showed a consistent trend which was largely 511 independent of polymer concentration. This allows a coarse prediction of expected behaviour, and 512 was also reported by Chesterton et al. (2011) for cake batters. The apparent extensional viscosity of 513 the guar gum solutions was estimated by monitoring the evolution of solution filament diameter as a 514 function of time using the method reported by Vadillo et al., 2010. For dilute solutions, below 10 
$515 \mathrm{~g} / \mathrm{L}$, the apparent extensional viscosity increases monotonically as a function of Hencky strain,

516 reaching a steady asymptotic value. The apparent extensional viscosity of the entangled solutions

517 also reaches a steady asymptote at high Hencky strain, but passes through a maximum value prior to

518 the asymptote. The asymptotic value of the apparent extensional viscosity is linearly proportional to

519 polymer concentration for both dilute and entangled regimes, with a squared correlation coefficient

520 of 0.995 . The peak apparent extensional viscosity, however, increases exponentially across the two

521 regimes as a function of polymer concentration with a squared correlation coefficient of 0.990 .

522

\section{Acknowledgements}

524 The authors acknowledge the financial support (POS-A/2012/116) from Xunta de Galicia's

525 Consellería de Cultura, Educación e Ordenación Universitaria of Spain and European Union’s

526 European Social Fund. We also wish to thank Dr Oren Scherman and Louisa Jane Quegan for

527 polymer chain length measurements, Tao Wang for his assistance with the surface tension

528 measurements, Dr Simon Butler for his help with the rheology experiments and Prof. Francis

529 Gadala-Maria for useful discussions. 
531 Anna, S. L., \& McKinley, G. H. (2001). Elasto-capillary thinning and breakup of model elastic liquids. Journal of Rheology, 45, 115-138.

533

534

535

536

537

538

539

540

541

542

543

544

545

546

547

548

549

550

551

552

553

554

555

556

557

558

559

560

561

562

563

564

565

566

567

Bazilevsky, A. V., Entov, V. M., \& Rozhkov, A. N. (1990). Liquid filament microrheometer and some of its applications. In D.R. Oliver (Eds.), Third European Rheology Conference (pp. 4143). New York: Elsevier.

Bazilevsky, A. V., Entov, V. M., Lerner, M. M., \& Rozhkov, A. N. (1997). Failure of polymer solution filaments. Polymer Science, Series A, 39, 316-324.

Bird, R. P., Curtiss, C. F., Armstrong, R. C., \& Hassager, O. (1987). Dynamics of Polymeric Liquids. (2nd ed.). New York: Wiley-Interscience, (Volumen 2: Kinetic Theory)

Bourbon, A. I., Pinheiro, A. C., Ribeiro, C., Miranda, C., Maia, J. M., Teixeira, J. A., \& Vicente, A. A. (2010). Characterization of galactomannans extracted from seeds of Gleditsia triacanthos and Sophora japonica through shear and extensional rheology: Comparison with guar gum and locust bean gum. Food Hydrocolloids, 24, 184-192.

Brenner, M. P., Lister, J. R., \& Stone, H. A. (1996). Pinching threads, singularities and the number 0.0304. Physics Fluids, 8, 2827-2836.

Chenlo, F., Moreira, R., Pereira, G., \& Silva, C. (2009). Rheological modelling of binary and ternary systems of tragacanth, guar gum and methylcellulose in dilute range of concentration at different temperatures. LWT - Food Science and Technology, 42, 519-524.

Chenlo, F., Moreira, R., \& Silva, C. (2010). Rheological properties of aqueous dispersions of tragacanth and guar gums at different concentrations. Journal of Texture Studies, 41, 396-415.

Chesterton, A. K. S., Meza, B. E., Moggridge, G. D., Sadd, P. A., \& Wilson, D. I. (2011). Rheological characterisation of cake batters generated by planetary mixing: elastic versus viscous effects. Journal of Food Engineering, 105, 332-342.

Cox, W. P., \& Merz, E. H. (1958). Correlation of dynamic and steady flow viscosities. Journal of Polymer Science, 28, 619-622.

Cross, M. M. (1965). Rheology of non-Newtonian fluids: a new flow equation for pseudoplastic systems. Journal of Colloid Science, 20, 417-437.

Cunha, P. L. R., Castro, R., Rocha, F., Paula, R. C. M., \& Feitosa, J. (2005). Low viscosity hydrogel of guar gum: preparation and physicochemical characterization. International Journal of Biological Macromolecules, 37, 99-104.

Cunha, P. L. R., de Paula, R. C. M., \& Feitosa, J. P. A. (2007). Purification of guar gum for biological applications. International Journal of Biological Macromolecules, 41, 324-331.

Durand, A. (2007). Aqueous solutions of amphiphilic polysaccharides: concentration and temperature effect on viscosity. European Polymer Journal, 43, 1744-1753.

Duxenneuner, M. R., Fischer, P., Windhab, E. J., \& Cooper-White, J. J. (2008). Extensional properties of hydroxypropyl ether guar gum solutions. Biomacromolecules, 9, 2989-2996. 
Eggers, J. (1997). Nonlinear dynamics and breakup of free-surface flows. Reviews of Modern Physics, 69(3), 865-926.

570

Entov, V. M., \& Hinch, E. J. (1997). Effect of a spectrum of relaxation times on the capillary thinning of a filament of elastic liquid. Journal of Non-Newtonian Fluid Mechanics, 72, 3154.

Gaume L. \& Forterre Y. (2007). A Viscoelastic Deadly Fluid in Carnivorous Pitcher Plants. PLoS ONE, 2(11), e1185.

Gupta, R. K., Nguyen, D. A., \& Sridhar, T. (2000). Extensional viscosity of dilute polystyrene solutions: Effect of concentration and molecular weight. Physics of Fluids, 12, 1296-1318.

Haward, J. S., Sharma, V., Butts, C. P., Mckinley, G. H., \& Rahatekar, S. S. (2012). Shear and extensional rheology of cellulose/ionic liquid solutions. Biomacromolecules, 13, 1688-1699.

Imeson, A. (2010). Food stabilisers, thickeners and gelling agents. Oxford, UK: Wiley-Blackwell.

Kulicke, W. M., Kiss, G., \& Porter, R. S. (1977). Inertial normal-force corrections in rotational geometry. Rheologica Acta, 16, 568-572.

Larson, G. (1988). Constitutive Equations for Polymer Melts and Solutions. Boston: Butterworths.

Launay, B., Cuvelier, G., \& Salomon, M. R. (1997). Viscosity of locust bean, guar and xanthan gum solutions in the Newtonian domain: a critical examination of $\log \left(\eta_{\mathrm{sp}}\right)_{\mathrm{o}}=\log \mathrm{C}[\eta]_{\mathrm{o}}$ master curves. Carbohydrate Polymers, 34, 385-395.

Liang, R. F., \& Mackley, M. R. (1994). Rheological characterization of the time and strain dependence for polyisobutylene solutions. Journal of Non-Newtonian Fluid Mechanical, 52, 387-405.

Macosko, C. W. (1994). Rheology: Principles, measurements, and applications. New York: Wiley.

Marangoni, A. G., \& Narine, S. S. (2002). Physical properties of lipids. Florida: CRC Press.

McKinley, G. H. (2005). Visco-elastic-capillary thinning and break-up of complex fluid. Rheology Reviews (The British Society of Rheology), 1-49.

McKinley, G. H., \& Tripathi, A. (2000). How to extract the Newtonian viscosity from capillary breakup measurements in a filament rheometer. Journal of Rheology, 44, 653-670.

Meza, B. E., Chesterton, A. K. S., Verdini, R. A., Rubiolo, A. C., Sadd, P. A., Moggridge, G. D., \& Wilson, D. I. (2011). Rheological characterisation of cake batters generated by planetary mixing: Comparison between untreated and heat-treated wheat flours. Journal of Food Engineering, 104, 592-602.

Miquelim, J. N., \& Lannes, S. C. D. S. (2009). Egg albumin and guar gum influence on foam thixotropy. Journal of Texture Studies, 40, 623-636.

Moreira, R., Chenlo, F., \& Torres, M. D. (2011). Rheological properties of commercial chestnut flour doughs with different gums. International Journal of Food Science and Technology, 46, 2085 - 2095. 
Moreira, R., Chenlo, F., Silva, C., Torres, M. D., Díaz-Varela, D., Hilliou, L., \& Argence, H. (2012). Surface tension and refractive index of guar and tragacanth gums aqueous dispersions at different polymer concentrations, polymer ratios and temperatures. Food Hydrocolloids, 28, 284-290.

Oblonsek, M., Sostar-Turk, S., \& Lapasin, R. (2003). Rheological studies of concentrated guar gum. Rheologica Acta, 42, 491-499.

Odell, J. A., \& Carrington, S. P. (2006). Extensional flow oscillatory rheometry. Journal of NonNewtonian Fluid Mechanics, 137, 110-112.

Padmanabhan, M. (1995). Measurement of extensional viscosity of viscoelastic liquid foods. Journal of Food Engineering, 25, 311-327.

Renardy, M. (1994). Some comments on the surface-tension driven breakup or the lack of it of viscoelastic jets. Journal of Non-Newtonian Fluid Mechanical, 51, 97-107.

Renardy, M. (1995). A numerical study of the asymptotic evolution and breakup of Newtonian and viscoelastic jets. Journal of Non-Newtonian Fluid Mechanical, 59, 267-282.

Rosell, C. M., Collar, C., \& Haros, M. (2007). Assessment of hydrocolloid effects on the thermomechanical properties of wheat using the Mixolab. Food Hydrocolloids, 21, 454-462.

Steffe, J. F. (1996). Rheological Methods in Food Process Engineering, Michigan: Freeman Press.

Szyszkowski, B. (1908). Experimentelle Studien über kapillare Eigenschaften der wässrigen Lösungen von Fettsäuren. Zeitschrift für Physikalische Chemie, 64, 385-414.

Sittikijyothin, W., Torres, D., \& Gonçalves, M. P. (2005). Modelling the rheological behaviour of galactomannan aqueous solutions. Carbohydrate Polymers, 59, 339-350.

Tembely M., Vadillo, D. C., Mackley, M. R., \& Soucemarianadin, A. (2012). The matching of a "one-dimensional" numerical simulation and experiment results for low viscosity Newtonian and non-Newtonian fluids during fast filament stretching and subsequent break-up. Journal of Rheology, 56, 159-184.

Tatham, J. P., Carrington, S., Odell, J. A., Gamboa, A. C., Muller, A. J., \& Saez, A. E. (1995). Extensional behavior of hydroxypropyl guar solutions: Optical rheometry in opposed jets and flow through porous media. Journal of Rheology, 39, 961-986.

Torres, M. D., Gadala-Maria, F., \& Wilson, D. I. (2013). Comparison of the rheology of bubbly liquids prepared by whisking air into a viscous liquid (honey) and a shear-thinning liquid (guar gum solutions). Journal of Food Engineering, 118, 213-228.

Tuladhar, T. R., Mackley, M. R. (2008). Filament stretching rheometry and break-up behaviour of low viscosity polymer solutions and ink jets fluids. Journal of Non-Newtonain Fluid Mechanics, 148, 97-108.

Vadillo, D. C., Mathues, W., \& Clasen, C. (2012a). Microsecond relaxation processes in shear and extensional flows of weakly elastic polymer solutions. Rheologica Acta, 51, 755-769. 
642 Vadillo, D. C., Tembely, M., Mackely, M. R., \& Soucemarianadin, A. (2012b). The matching of 643 polymer solution fast filament stretching, relaxation, and break up experimental results with 644 1D and 2D numerical viscoelastic simulation. Journal of Rheology, 56, 1491-1516.

645 Vadillo, D. C., Tuladhar, T. R., Mulji, A. C., Jung, S., Hoath, S. D., \& Mackley, M. R. (2010). 646 Evaluation of the inkjet fluid's performance using the "Cambridge Trimaster" filament 647 stretch and break-up device. Journal of Rheology, 54, 261-282.

648 Yesilata, B., Clasen, C. \& McKinley, G. (2006). Nonlinear shear and extensional flow dynamics of 649 wormlike surfactant solutions. Journal of Non-Newtonain Fluid Mechanics, 133, 73-90. 
651 Figure 1 Effect of guar gum concentration on surface tension relative to water. Solid trend line

652

653

654

655

656

657

658

659

660

661

662

663

664

665

666

667

668

669

670

671

672

673

674

675

676

677

678

679

680

681

682

683

684

685

686 shows Equation [12] fitted to the guar gum data with parameters $a=0.0123$ and $b=0.0045$ g/L. Experimental data showed high reproducibility and estimated uncertainty is smaller than symbol size.

Figure 2 Flow curves of aqueous guar gum solutions prepared at several concentrations. Symbols: circles $-1 \mathrm{~g} / \mathrm{L}$, triangles $-2 \mathrm{~g} / \mathrm{L}$, squares $-5 \mathrm{~g} / \mathrm{L}$, diamonds $-10 \mathrm{~g} / \mathrm{L}$, dashes $-15 \mathrm{~g} / \mathrm{L}$, crosses $-20 \mathrm{~g} / \mathrm{L}$. The solid line shows the best fit to the guar gum solutions obtained with the Cross model (Equation [2]), with parameters given in Table 1. In this and subsequent plots, error bars are not plotted if the uncertainty in data values is smaller than the symbol size.

Figure 3 Stress parameters measured for aqueous guar gum solutions prepared at different polymer concentration: (a) normal stress differences $\left(N_{1}-N_{2}\right)$ and (b) estimated Weissenberg number $(=(\mathrm{N} 1-\mathrm{N} 2) / \tau)$. Symbols: circles $-1 \mathrm{~g} / \mathrm{L}$, triangles $-2 \mathrm{~g} / \mathrm{L}$, squares $-5 \mathrm{~g} / \mathrm{L}$, diamonds -10 $\mathrm{g} / \mathrm{L}$, dashes $-15 \mathrm{~g} / \mathrm{L}$, crosses $-20 \mathrm{~g} / \mathrm{L}$.

Figure 4 Mechanical spectra of representative aqueous guar gum solutions prepared at concentrations of (a) 1, 5, (b) 10 and $20 \mathrm{~g} / \mathrm{L}$. Symbols: closed $-\mathrm{G}^{\prime}$, open $-\mathrm{G}^{\prime \prime}$, circles -1 $\mathrm{g} / \mathrm{L}$, squares $-5 \mathrm{~g} / \mathrm{L}$, diamonds $-10 \mathrm{~g} / \mathrm{L}$, triangles $-20 \mathrm{~g} / \mathrm{L}$. Solid and dashed lines in (b) shows $\mathrm{G}^{\prime}$ and $\mathrm{G}^{\prime \prime}$ values for aqueous guar gum solution at $5 \mathrm{~g} / \mathrm{L}$, respectively.

Figure 5 Comparison between the apparent viscosity (symbols) and the complex viscosity (dashed lines) for aqueous guar gum solutions prepared at several concentrations, Cox-Merz rule (Cox \& Merz, 1958). Symbols: circles $-1 \mathrm{~g} / \mathrm{L}$, triangles $-2 \mathrm{~g} / \mathrm{L}$, squares $-5 \mathrm{~g} / \mathrm{L}$, diamonds $10 \mathrm{~g} / \mathrm{L}$, dashes $-15 \mathrm{~g} / \mathrm{L}$, crosses $-20 \mathrm{~g} / \mathrm{L}$.

Figure 6 Dimensionless filament diameter profiles for aqueous guar gum solutions prepared at several concentrations. Symbols: circles $-1 \mathrm{~g} / \mathrm{L}$, triangles $-2 \mathrm{~g} / \mathrm{L}$, squares $-5 \mathrm{~g} / \mathrm{L}$, diamonds - $10 \mathrm{~g} / \mathrm{L}$, dashes $-15 \mathrm{~g} / \mathrm{L}$, crosses $-20 \mathrm{~g} / \mathrm{L}$. The non-linear profiles indicate nonNewtonian behaviour.

Figure 7 Correlation between time break-up $\left(\mathrm{t}_{\mathrm{F}}\right)$ and polymer concentration $(\mathrm{C})$ or initial filament diameter $\left(D_{1}\right)$ for aqueous guar gum solutions prepared at several concentrations. Dashed lines show exponential trends: $t_{F}-t_{F 0}=\left(1-\mathrm{e}^{\mathrm{C} / 20}\right)$ and $t_{F}=15.2 \mathrm{e}^{0.0042 \mathrm{D}_{\mathrm{i}}}\left(R^{2}=0.998\right)$. 
Figure 8 Dimensionless filament diameter profiles with dimensionless time for aqueous guar gum solutions prepared at several concentrations. Symbols: circles $-1 \mathrm{~g} / \mathrm{L}$, triangles $-2 \mathrm{~g} / \mathrm{L}$, squares $-5 \mathrm{~g} / \mathrm{L}$, diamonds $-10 \mathrm{~g} / \mathrm{L}$, dashes $-15 \mathrm{~g} / \mathrm{L}$, crosses $-20 \mathrm{~g} / \mathrm{L}$.

690

Figure 9 Dimensionless filament diameter profiles with time for representative aqueous guar gum solutions prepared at $10 \mathrm{~g} / \mathrm{L}$. Dashed lines shows the fitting achieved with Equation [9] and solid lines with Equation [16].

694

Figure 10 Effect of polymer concentration on initial relaxation time $\left(\lambda_{1}\right)$ and parameter $b^{\prime}$ (Equation [16]) for aqueous guar gum solutions prepared at several concentrations. Open symbols, $\lambda_{1}$; and closed symbols, $b$ '. Dashed line shows the power-law trend obtained for $\lambda_{1}$ by

Figure 11 Correlation between initial relaxation time $\left(\lambda_{1}\right)$ and break-up time $\left(t_{F}\right)$ for aqueous guar gum solutions prepared at labelled concentrations. Dashed line shows linear trend, with $t_{F}=$

Figure 12 Extensional viscosity versus (a) Hencky strain and (b) polymer concentration $(C)$ for $8.06 \lambda_{1}-34.3\left(R^{2}=0.987\right)$.

Figure 13 Correlation between Trouton ratio and (a) Hencky strain and (b) polymer concentration for guar gum solutions. Symbols: circles $-1 \mathrm{~g} / \mathrm{L}$, triangles $-2 \mathrm{~g} / \mathrm{L}$, squares $-5 \mathrm{~g} / \mathrm{L}$, diamonds - $10 \mathrm{~g} / \mathrm{L}$, dashes $-15 \mathrm{~g} / \mathrm{L}$, crosses - $20 \mathrm{~g} / \mathrm{L}$. Dashed line in (b) shows the trend obtained by Duxenneuner et al. (2008). $\mathrm{N}_{\mathrm{TR}}$ in (b) evaluated at $0.1 \mathrm{~s}^{-1}$. 


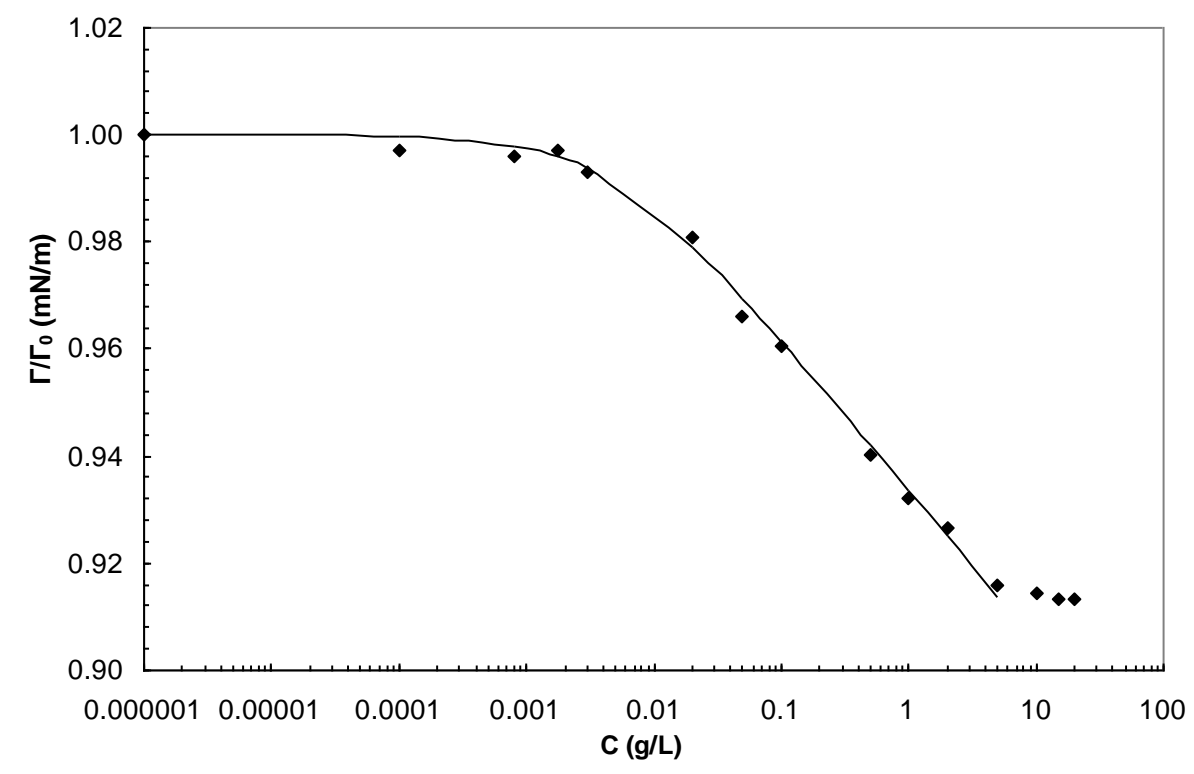

714

715

716 Figure 1 Effect of guar gum concentration on surface tension relative to water. Solid trend line 717 shows Equation [12] fitted to the guar gum data with parameters $a=0.0123$ and $b=0.0045$ $\mathrm{g} / \mathrm{L}$. Experimental data showed high reproducibility and estimated uncertainty is smaller than symbol size. 


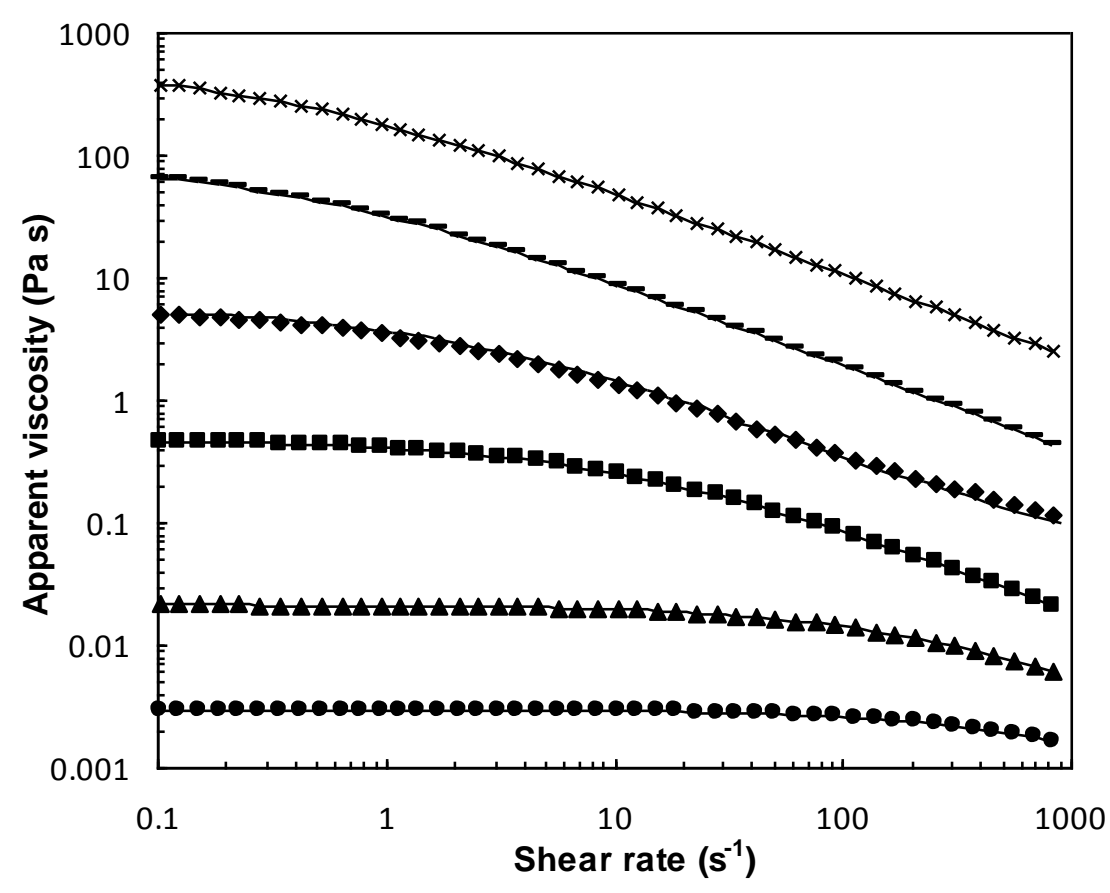

Figure 2 Flow curves of aqueous guar gum solutions prepared at several concentrations. Symbols: circles $-1 \mathrm{~g} / \mathrm{L}$, triangles $-2 \mathrm{~g} / \mathrm{L}$, squares $-5 \mathrm{~g} / \mathrm{L}$, diamonds $-10 \mathrm{~g} / \mathrm{L}$, dashes $-15 \mathrm{~g} / \mathrm{L}$, crosses - $20 \mathrm{~g} / \mathrm{L}$. The solid line shows the best fit to the guar gum solutions obtained with the Cross model (Equation [2]), with parameters given in Table 1. In this and subsequent plots, error bars are not plotted if the uncertainty in data values is smaller than the symbol size. 
(a)

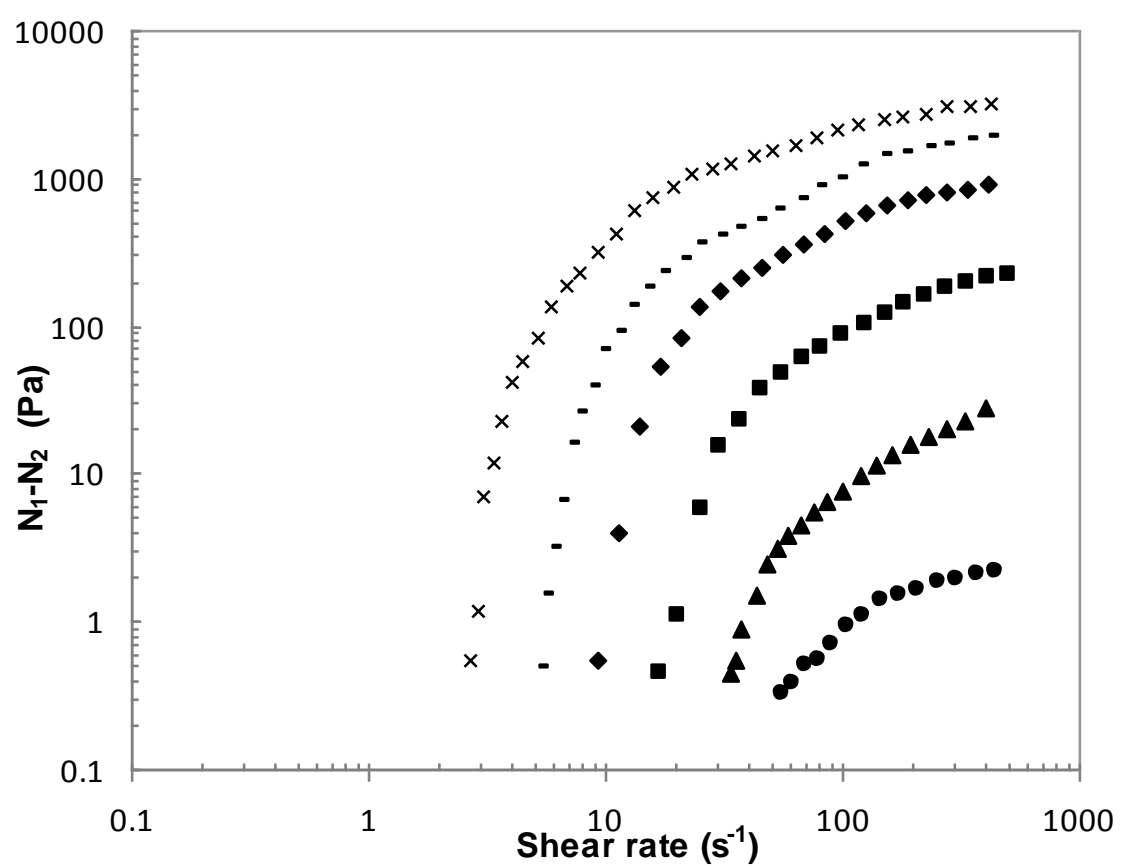

$731 \quad(b)$

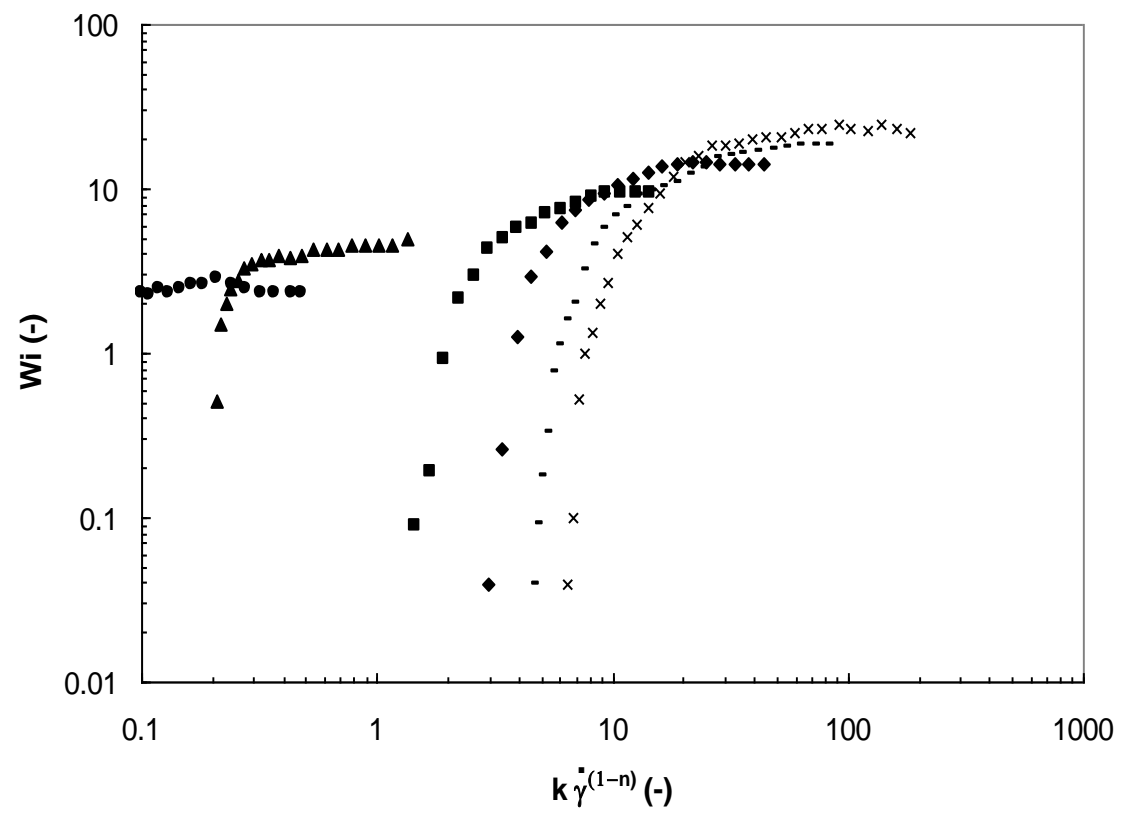

732

733 Figure 3 Stress parameters measured for aqueous guar gum solutions prepared at different polymer concentration: (a) normal stress differences $\left(N_{1}-N_{2}\right)$ and (b) estimated Weissenberg number $(=(\mathrm{N} 1-\mathrm{N} 2) / \tau)$. Symbols: circles $-1 \mathrm{~g} / \mathrm{L}$, triangles $-2 \mathrm{~g} / \mathrm{L}$, squares $-5 \mathrm{~g} / \mathrm{L}$, diamonds -10 $\mathrm{g} / \mathrm{L}$, dashes $-15 \mathrm{~g} / \mathrm{L}$, crosses $-20 \mathrm{~g} / \mathrm{L}$. 
(a)

738

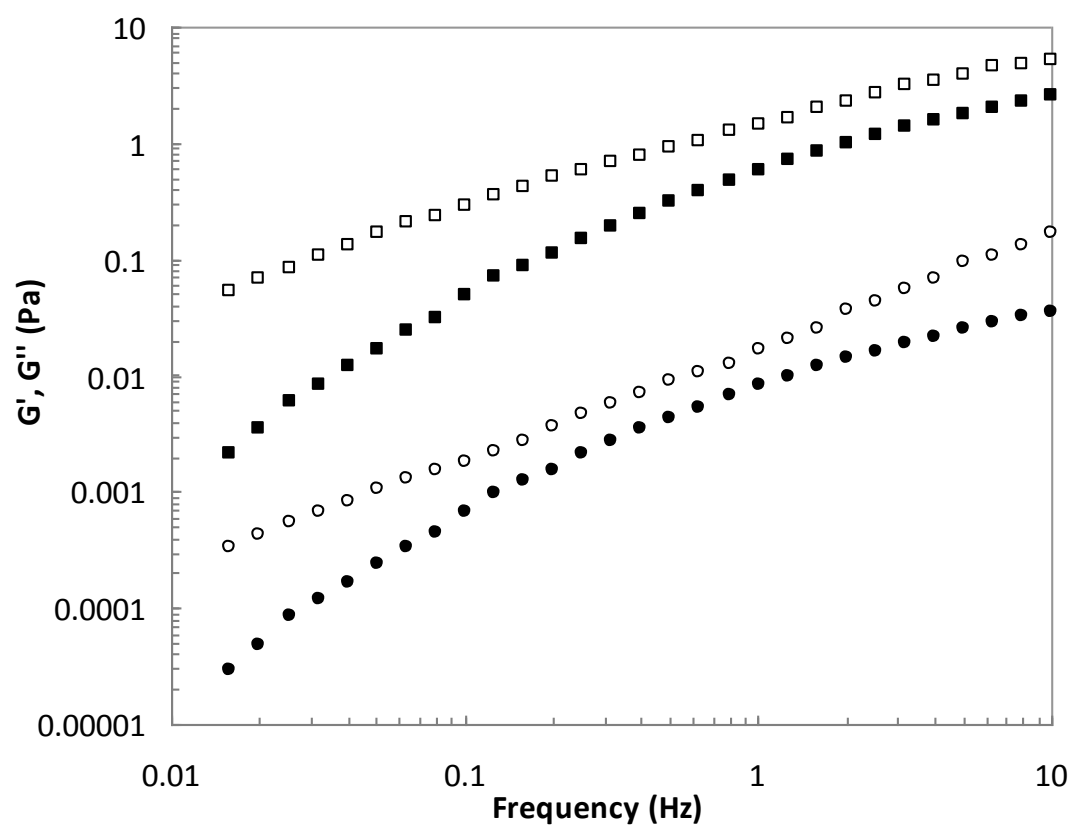

739

(b)

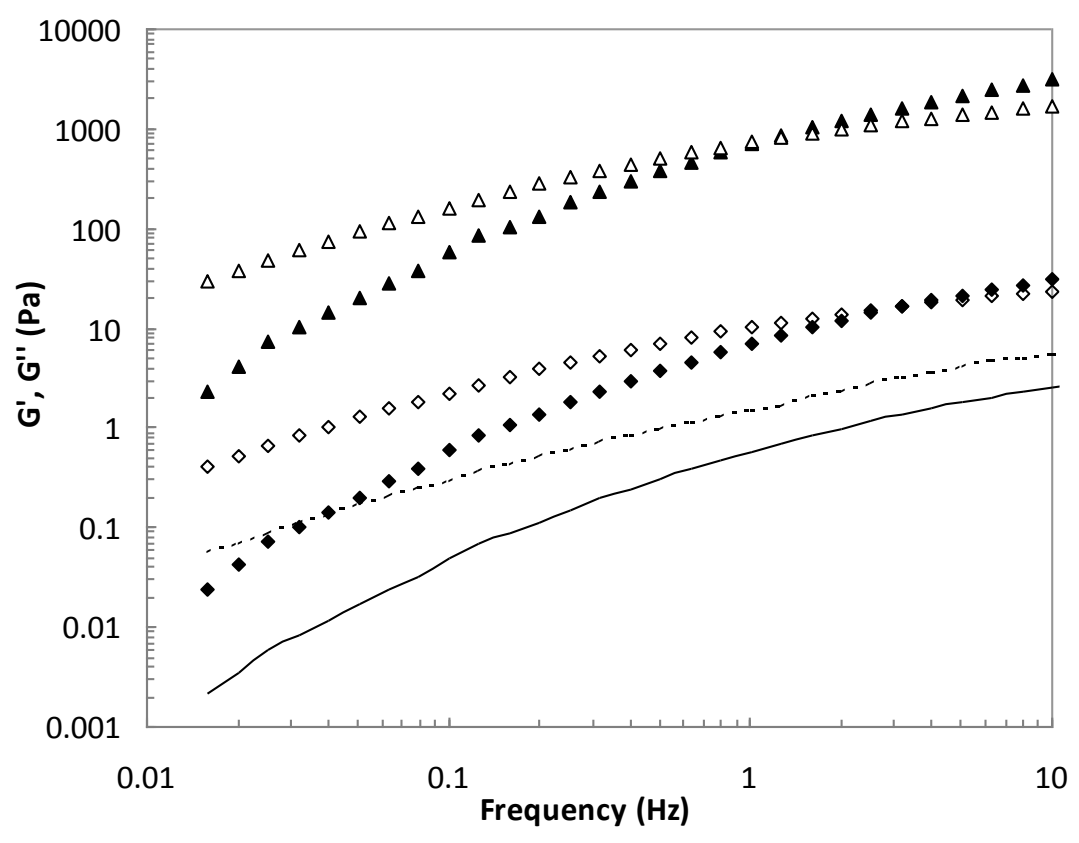

741

742 Figure 4 Mechanical spectra of representative aqueous guar gum solutions prepared at concentrations of (a) 1, 5, (b) 10 and $20 \mathrm{~g} / \mathrm{L}$. Symbols: closed - G', open - G", circles -1 $\mathrm{g} / \mathrm{L}$, squares $-5 \mathrm{~g} / \mathrm{L}$, diamonds $-10 \mathrm{~g} / \mathrm{L}$, triangles $-20 \mathrm{~g} / \mathrm{L}$. Solid and dashed lines in (b) shows $\mathrm{G}^{\prime}$ and $\mathrm{G}^{\prime \prime}$ values for aqueous guar gum solution at $5 \mathrm{~g} / \mathrm{L}$, respectively. 


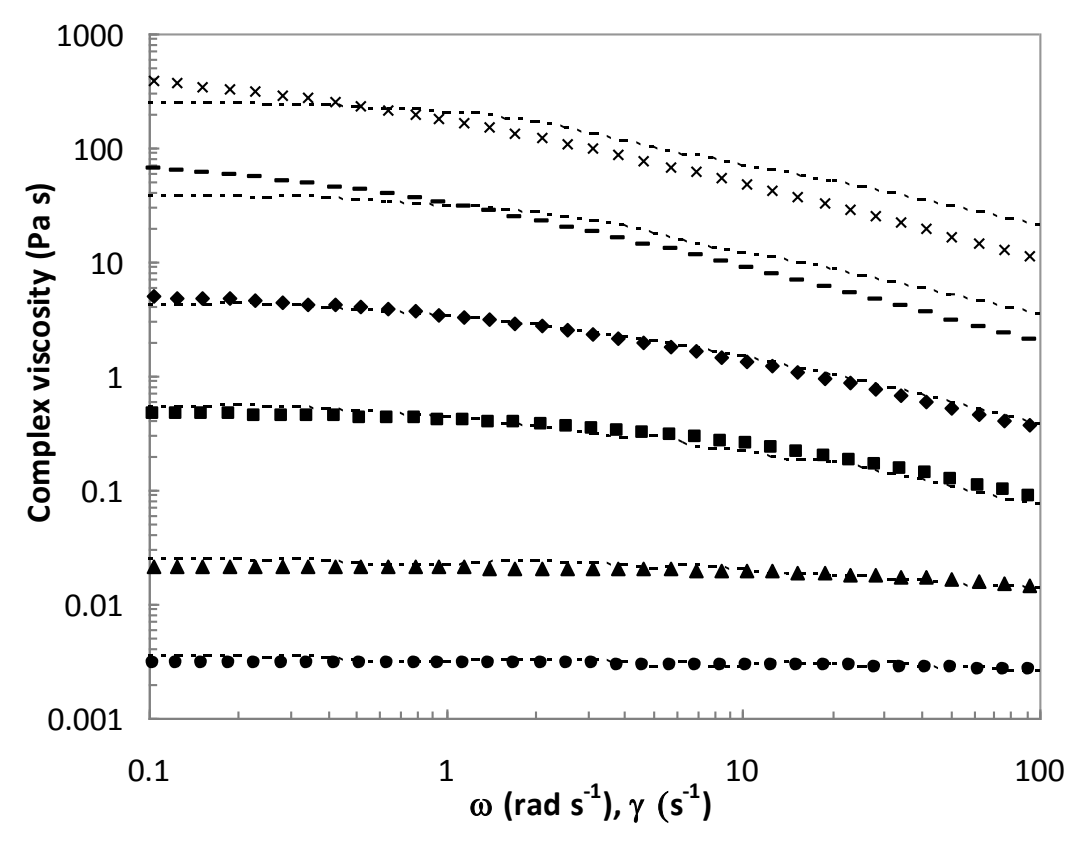

748 Figure 5 Comparison between the apparent viscosity (symbols) and the complex viscosity (dashed lines) for aqueous guar gum solutions prepared at several concentrations, Cox-Merz rule (Cox \& Merz, 1958). Symbols: circles $-1 \mathrm{~g} / \mathrm{L}$, triangles $-2 \mathrm{~g} / \mathrm{L}$, squares $-5 \mathrm{~g} / \mathrm{L}$, diamonds $10 \mathrm{~g} / \mathrm{L}$, dashes $-15 \mathrm{~g} / \mathrm{L}$, crosses $-20 \mathrm{~g} / \mathrm{L}$. 


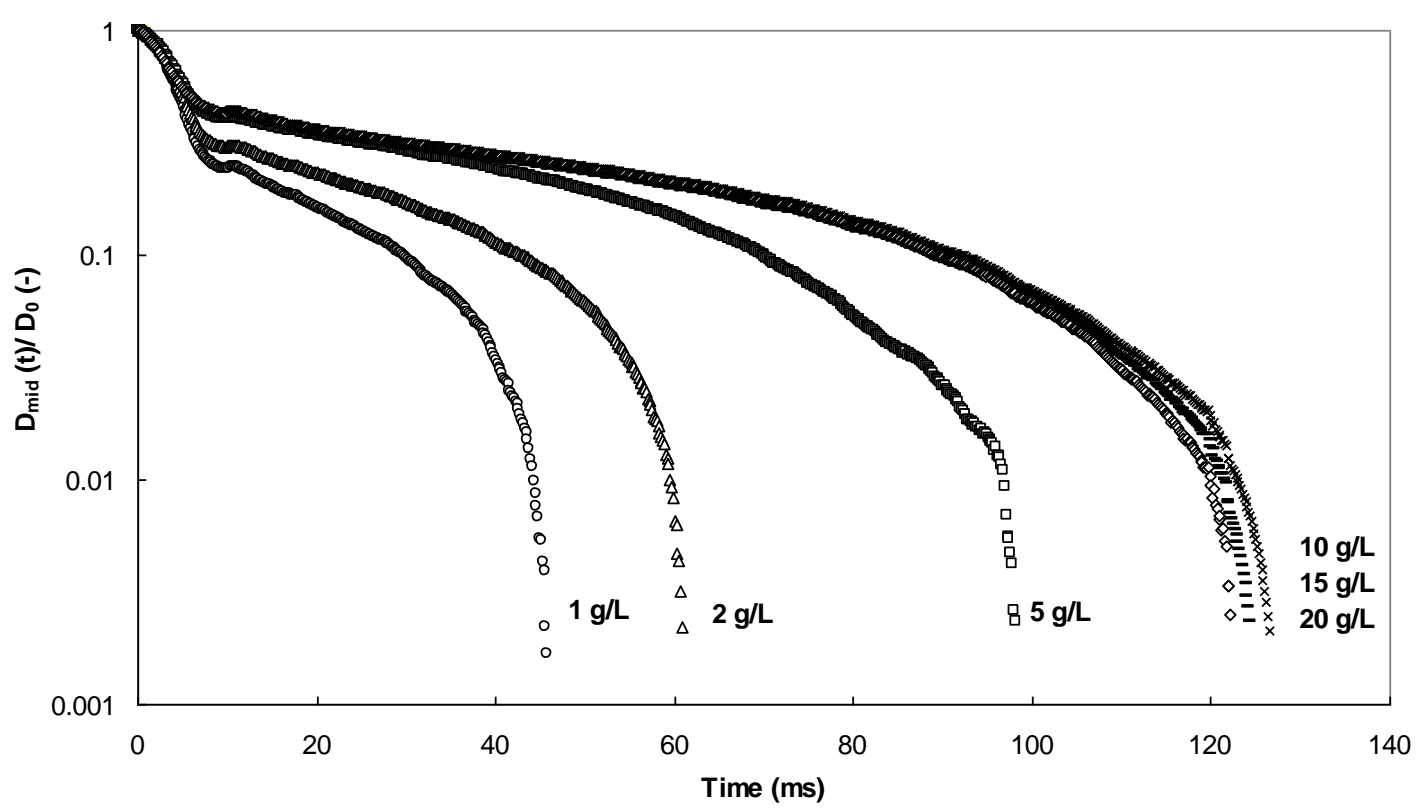

Figure 6 Dimensionless filament diameter profiles for aqueous guar gum solutions prepared at several concentrations. Symbols: circles $-1 \mathrm{~g} / \mathrm{L}$, triangles $-2 \mathrm{~g} / \mathrm{L}$, squares $-5 \mathrm{~g} / \mathrm{L}$, diamonds - $10 \mathrm{~g} / \mathrm{L}$, dashes $-15 \mathrm{~g} / \mathrm{L}$, crosses - $20 \mathrm{~g} / \mathrm{L}$. The non-linear profiles indicate nonNewtonian behaviour. 


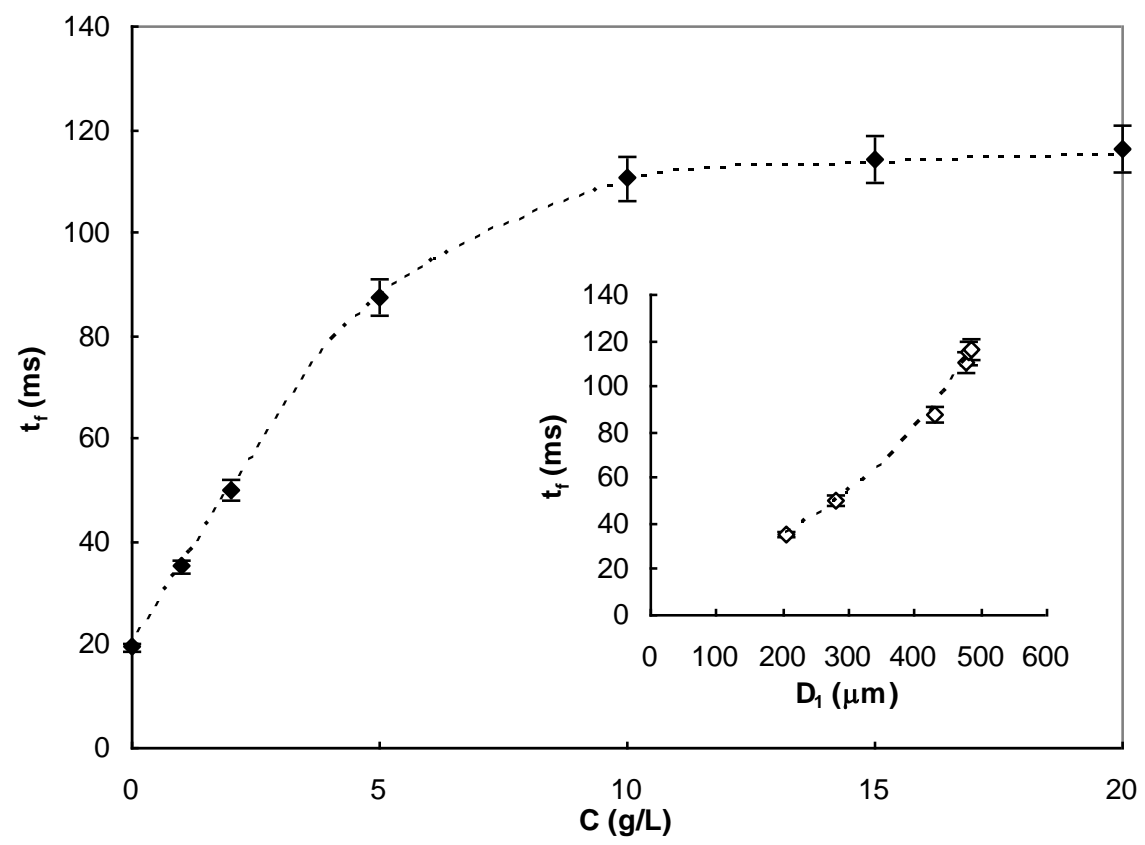

759

760

Figure 7 Correlation between time break-up $\left(\mathrm{t}_{\mathrm{F}}\right)$ and polymer concentration $(\mathrm{C})$ or initial filament diameter $\left(D_{1}\right)$ for aqueous guar gum solutions prepared at several concentrations. Dashed lines show exponential trends: $t_{F}-t_{F 0}=\left(1-\mathrm{e}^{\mathrm{C} / 20}\right)$ and $t_{F}=15.2 \mathrm{e}^{0.0042 \mathrm{D}_{\mathrm{D}}}\left(R^{2}=0.998\right)$. 


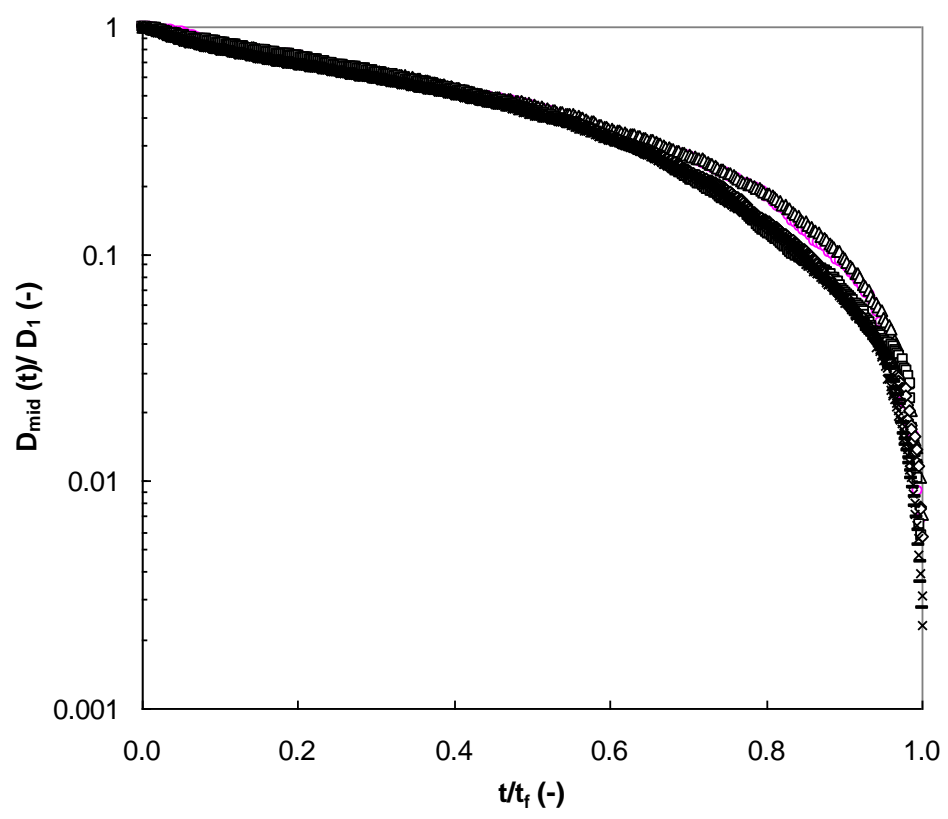

764

765

766 Figure 8 Dimensionless filament diameter profiles with dimensionless time for aqueous guar gum 767 solutions prepared at several concentrations. Symbols: circles $-1 \mathrm{~g} / \mathrm{L}$, triangles $-2 \mathrm{~g} / \mathrm{L}$, 768 squares $-5 \mathrm{~g} / \mathrm{L}$, diamonds $-10 \mathrm{~g} / \mathrm{L}$, dashes $-15 \mathrm{~g} / \mathrm{L}$, crosses $-20 \mathrm{~g} / \mathrm{L}$. 


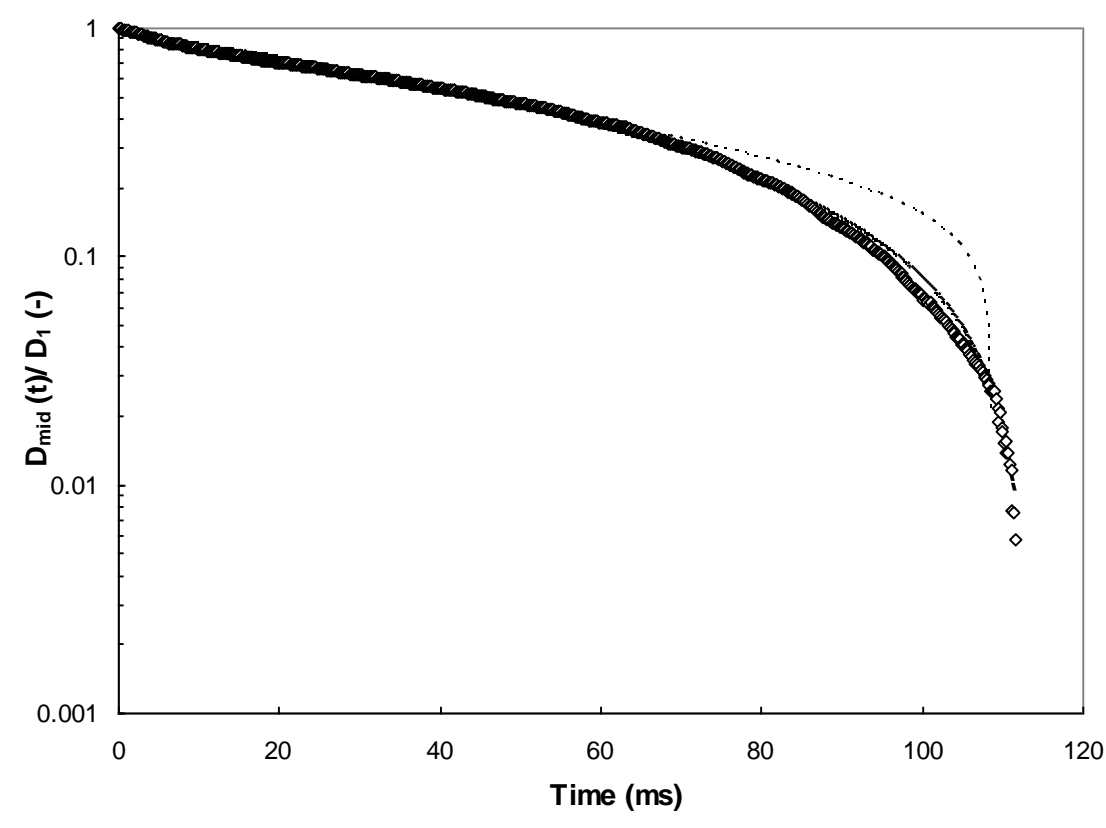

772 Figure 9 Dimensionless filament diameter profiles with time for representative aqueous guar gum solutions prepared at $10 \mathrm{~g} / \mathrm{L}$. Dashed lines shows the fitting achieved with Equation [9] and solid lines with Equation [16].

775

776 
(a)

778

779

780

781

782

783

784

785

786

787

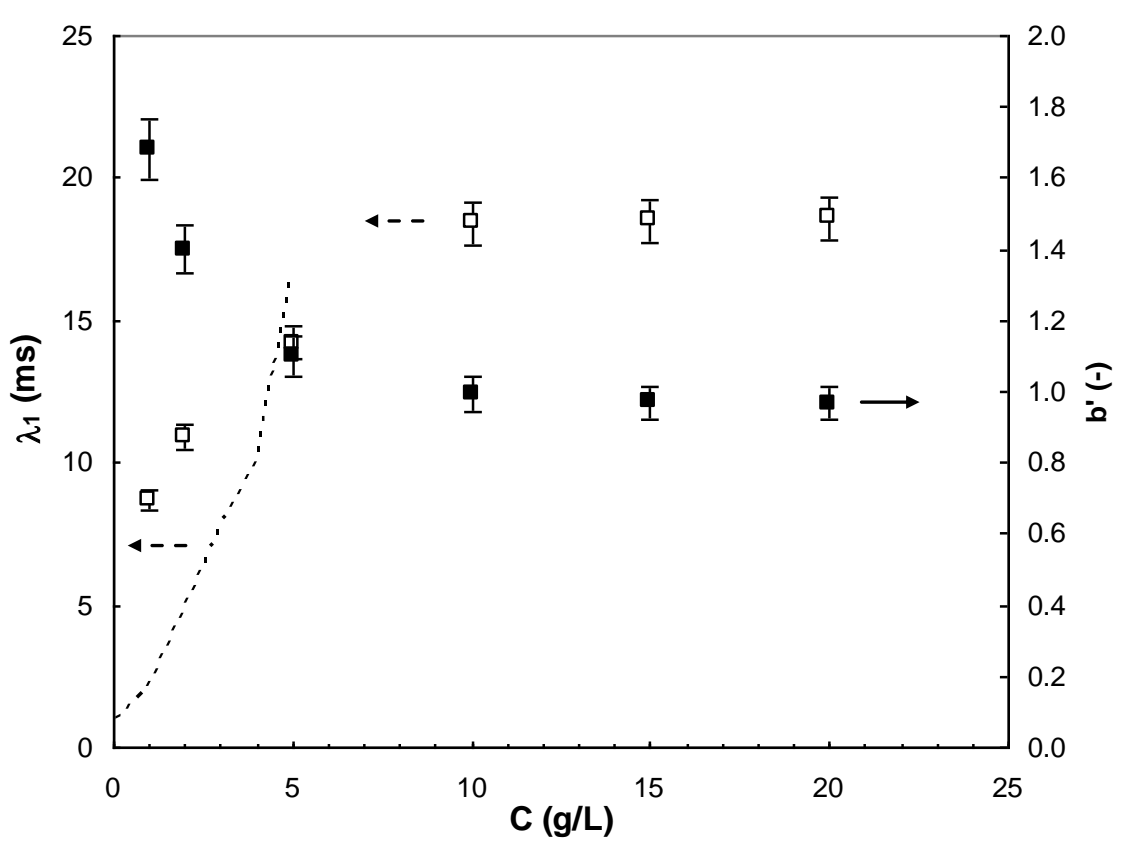

(b)

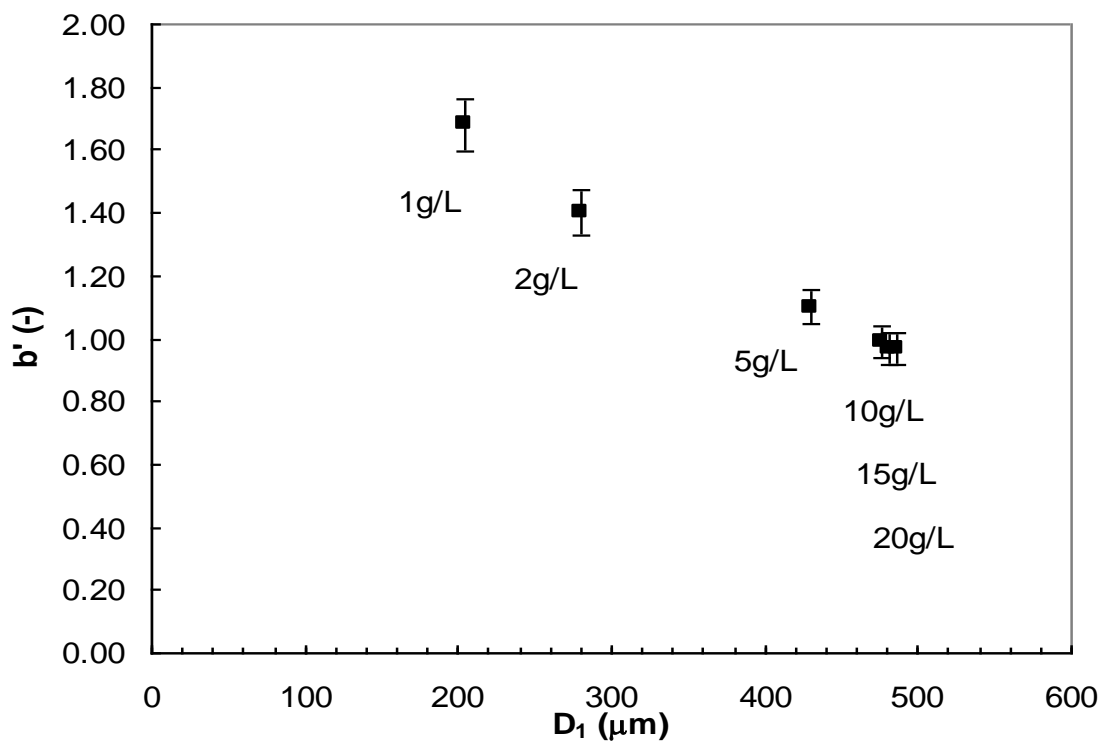

Figure 10 (a) Effect of polymer concentration on initial relaxation time $\left(\lambda_{1}\right)$ and parameter $b^{\prime}$ (Equation [16]) for aqueous guar gum solutions prepared at several concentrations. Open symbols, $\lambda_{1}$; and closed symbols, $b^{\prime}$. Dashed line shows the power-law trend obtained for $\lambda_{1}$ by Duxenneuner et al. (2008). (b) Relationship between parameter $b^{\prime}$ (Equation [16]) and filament formation diameter $\left(D_{1}\right)$ for aqueous guar gum solutions prepared at several concentrations. 


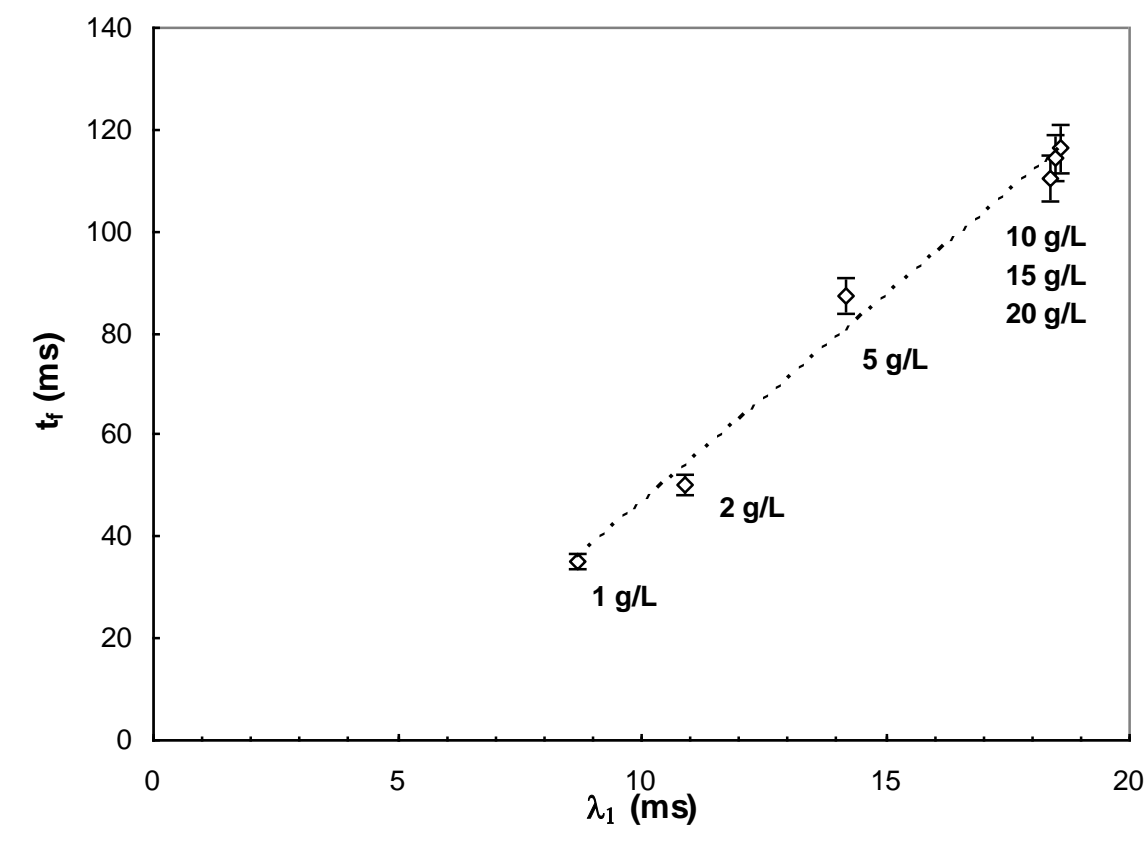

788

789

790 Figure 11 Correlation between initial relaxation time $\left(\lambda_{1}\right)$ and break-up time $\left(t_{F}\right)$ for aqueous guar 791 gum solutions prepared at labelled concentrations. Dashed line shows linear trend, with $t_{F}=$ $8.06 \lambda_{1}-34.3\left(R^{2}=0.987\right)$. 


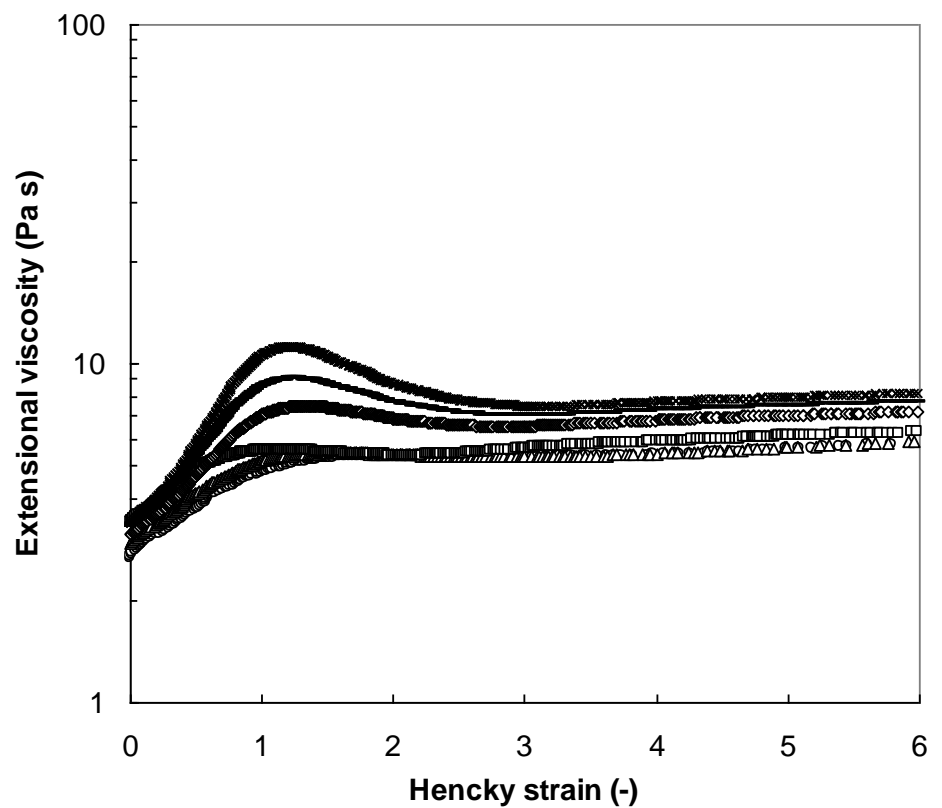

795

(b)

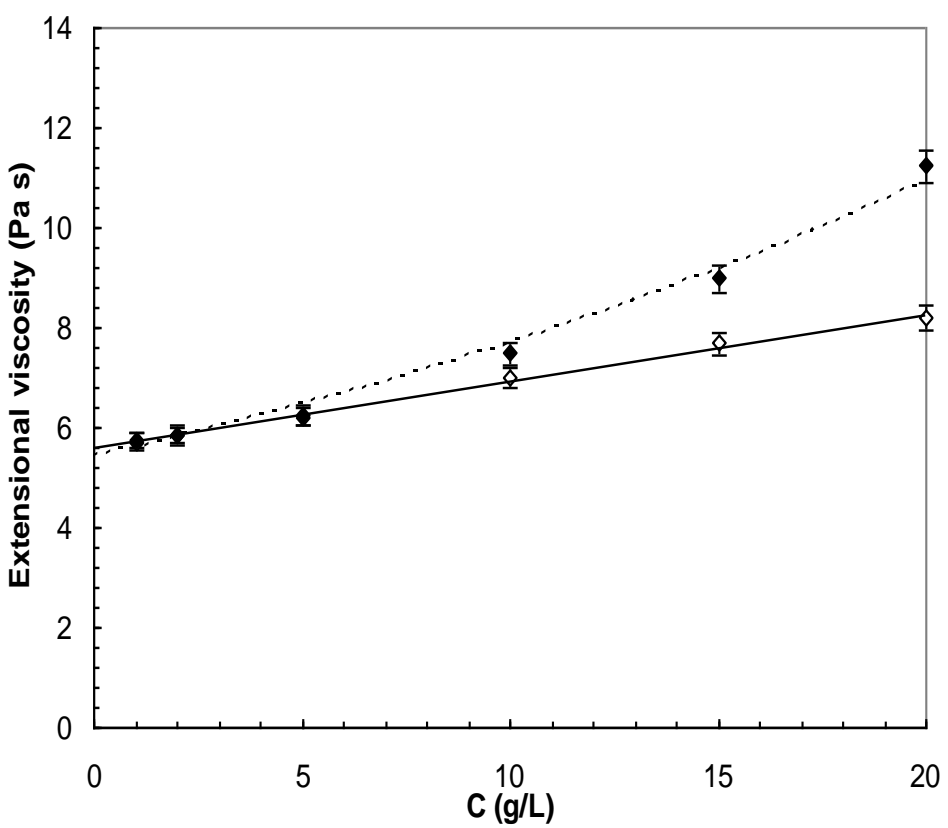

Figure 12 Extensional viscosity versus (a) Hencky strain and (b) polymer concentration $(C)$ for aqueous guar gum solutions. Symbols: circles $-1 \mathrm{~g} / \mathrm{L}$, triangles $-2 \mathrm{~g} / \mathrm{L}$, squares $-5 \mathrm{~g} / \mathrm{L}$, diamonds - $10 \mathrm{~g} / \mathrm{L}$, dashes $-15 \mathrm{~g} / \mathrm{L}$, crosses $-20 \mathrm{~g} / \mathrm{L}$. Dashed line (maximum extensional viscosities) shows exponential trend, with $\eta_{e}=5.4 \mathrm{e}^{0.035 \mathrm{C}}\left(R^{2}=0.990\right)$. Solid line (steady extensional viscosities) shows linear trend, with $\eta_{e}=0.14 \mathrm{C}+5.6\left(\mathrm{R}^{2}=0.995\right)$. 


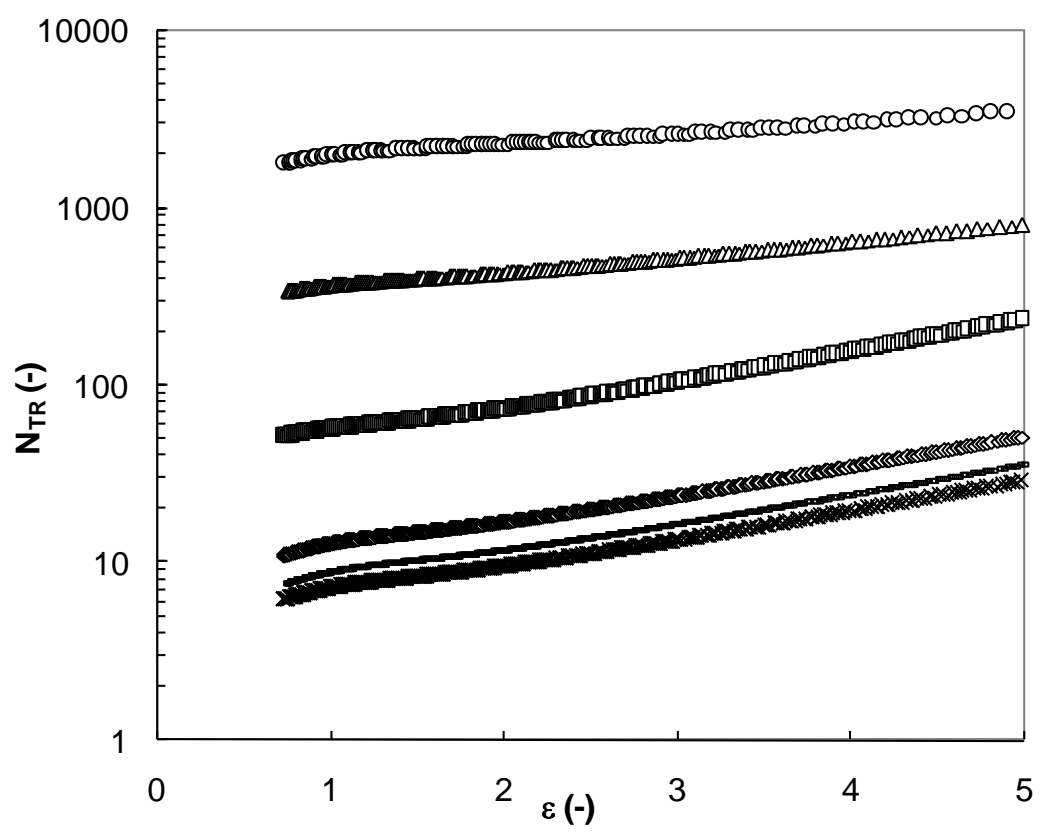

804 (b)

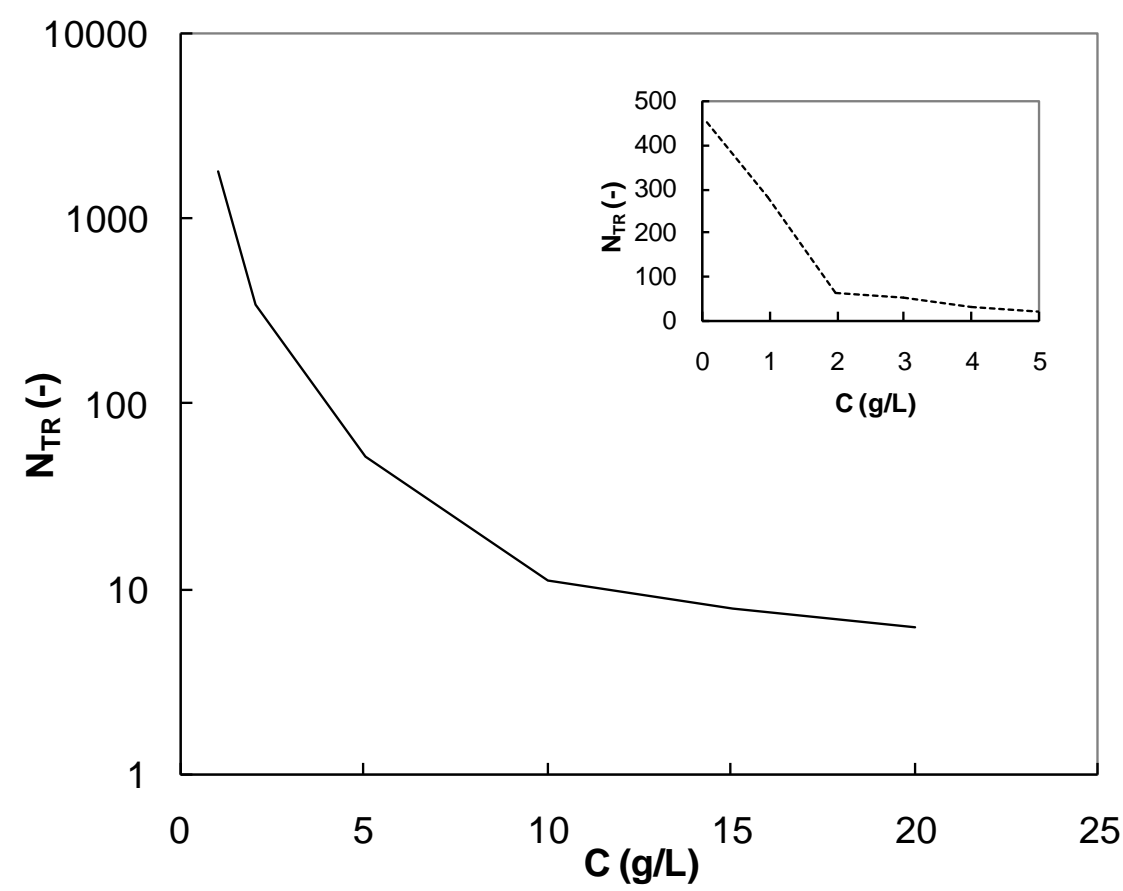

806 Figure 13 Correlation between Trouton ratio and (a) Hencky strain and (b) polymer concentration for guar gum solutions. Symbols: circles $-1 \mathrm{~g} / \mathrm{L}$, triangles $-2 \mathrm{~g} / \mathrm{L}$, squares $-5 \mathrm{~g} / \mathrm{L}$, diamonds - $10 \mathrm{~g} / \mathrm{L}$, dashes $-15 \mathrm{~g} / \mathrm{L}$, crosses $-20 \mathrm{~g} / \mathrm{L}$. Dashed line in (b) shows the trend obtained by Duxenneuner et al. (2008). $N_{\mathrm{TR}}$ in (b) evaluated at $0.1 \mathrm{~s}^{-1}$. 


\section{Table Captions}

811 Table 1 Parameter values obtained for Cross-Williamson model, Equation [2], for aqueous 812 guar gum solutions prepared at several concentrations. 
813 Table 1 Parameter values obtained for Cross-Williamson model, Equation [2], for aqueous 814 guar gum solutions prepared at several concentrations. ${ }^{\dagger}$

815

\begin{tabular}{cccccc}
\hline $\begin{array}{c}\text { Concentration } \\
(\mathrm{g} / \mathrm{L})\end{array}$ & $\begin{array}{c}\eta_{0} \\
(\mathrm{~Pa} \mathrm{~s})\end{array}$ & $\begin{array}{c}k \\
\left(\mathrm{~s}^{1-\mathrm{n}}\right)\end{array}$ & $\begin{array}{c}n \\
(-)\end{array}$ & $\begin{array}{c}R^{2} \\
\text { Standard deviation } \\
(\mathrm{Pa} \mathrm{s})\end{array}$ \\
\hline 2 & $0.0031 \pm 0.0002^{\mathrm{f}}$ & $0.0045 \pm 0.0002^{\mathrm{f}}$ & $0.23 \pm 0.01^{\mathrm{c}}$ & 0.999 & 0.025 \\
& $0.0215 \pm 0.0001^{\mathrm{e}}$ & $0.015 \pm 0.011^{\mathrm{e}}$ & $0.25 \pm 0.01^{\mathrm{b}}$ & 0.998 & 0.027 \\
5 & $0.48 \pm 0.02^{\mathrm{d}}$ & $0.19 \pm 0.01^{\mathrm{d}}$ & $0.28 \pm 0.01^{\mathrm{a}, \mathrm{b}}$ & 0.999 & 0.026 \\
10 & $5.87 \pm 0.01^{\mathrm{c}}$ & $0.61 \pm 0.01^{\mathrm{c}}$ & $0.29 \pm 0.01^{\mathrm{a}}$ & 0.997 & 0.030 \\
15 & $89.5 \pm 2.3^{\mathrm{b}}$ & $1.81 \pm 0.01^{\mathrm{b}}$ & $0.30 \pm 0.01^{\mathrm{a}}$ & 0.996 & 0.032 \\
& & & & & \\
20 & $550 \pm 10.4^{\mathrm{a}}$ & $2.20 \pm 0.01^{\mathrm{a}}$ & $0.31 \pm 0.01^{\mathrm{a}}$ & 0.997 & 0.029
\end{tabular}

816

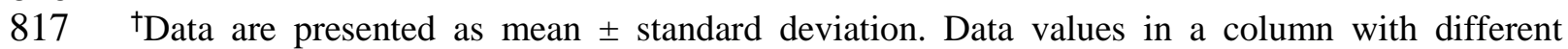
818 superscript letters are significantly different at the $p \leq 0.05$ level.

819

820 